\title{
Inappropriate prescribing, non-adherence to long-term medications and related morbidities Pharmacoepidemiological aspects
}

\author{
Khedidja Hedna \\ Division of Drug Research \\ Department of Medical and Health Sciences \\ Linköping University \\ LINKŎPING \\ UNIVERSITY
}

Linköping, Sweden 2015 
Inappropriate prescribing, non-adherence to long-term medications and related morbidities (C) Khedidja Hedna 2015

Khedidja.hedna@liu.se

ISBN: 978-91-7519-025-9

ISSN: 0345-0082

Printed by Liu-Tryck, Linköping, Sweden 2015 
All the passionate work I put into my research is dedicated to my parents, who always considered education and values the highest of priorities. 


\title{
Inappropriate prescribing, non-adherence to long- term medications and related morbidities
}

\author{
Pharmacoepidemiological aspects
}

\author{
Khedidja Hedna \\ Division of Drug Research \\ Department of Medical and Health Sciences \\ Linköping University, Linköping, Sweden
}

\begin{abstract}
Background: Inappropriate use of medications (IUM), in particular inappropriate prescribing and non-adherence to prescribed medications, are important causes of drug-related morbidities (DRMs). They are increasing problems with the ageing populations and the growing burden of chronic conditions. However, research is needed on the association of IUMs with DRMs in outpatient settings and in the general population.
\end{abstract}

\begin{abstract}
Aim: The aim of this thesis is to estimate and analyse the burden of potentially inappropriate prescriptions (PIPs) in the elderly and non-adherence to long-term medications among adults across care settings, and to investigate how IUM is associated to DRMs.
\end{abstract}

Methods: A meta-analysis summarised the previous evidence on the percentage of adverse drug reactions (ADRs) associated to IUM across healthcare settings (Study I). From a cohort in the general population, using medical records and register data, the prevalence of PIPs in the elderly and its association with ADRs were estimated retrospectively (Study II). From the same cohort, the factors associated with refill non-adherence to antihypertensive therapy, considering the use of multiple medications, and the association between non-adherence and sub-therapeutic effects (STEs) were investigated (Study III). A survey assessed the refill behaviour to antihypertensive, lipid lowering and oral antidiabetic medications (undersupply, adequate supply and oversupply), and its association with perceived ADRs and STEs (Study IV).

Results: IUM was the cause $52 \%$ and $45 \%$ of ADRs occurring in adult outpatients and inpatients respectively. Across healthcare settings, $46 \%$ of the elderly refilled PIPs over a 6-month period; PIPs were considered the cause of $30 \%$ of all ADRs; and the elderly who were prescribed PIPs had increased odds to experience ADRs (OR 2.47, 95\% CI 1.65-3.69). In total, 35\% was nonadherent to the full multidrug therapy and $13 \%$ was non-adherent to any medication (complete 
non-adherence). Sociodemographic factors (working age and lower income) were associated with non-adherence to any medication, while clinical factors (use of specialised care, use of multiple medications, and being a new user) with non-adherence to the full multidrug therapy. STEs were associated with non-adherence to any medication a month prior to a healthcare visit (OR 3.27, 95\% CI 1.27-8.49), but not with long-term measures of non-adherence. Among survey respondents, $22 \%$ of the medications were oversupplied and $12 \%$ were undersupplied. Inadequate refill behaviour was not associated with reporting ADRs or STEs $(\mathrm{p}<0.05)$.

Conclusions: A large proportion of ADRs occurring in hospital is caused by IUM, but more knowledge is needed in other settings. PIPs are common in the elderly general population and associated with ADRs. Therefore decreasing PIPs could contribute towards ADR prevention. Considering the use of multiple medications may help to better understand the factors associated with non-adherence to a multidrug therapy for tailoring the interventions to patient needs. Monitoring the adherence prior to a healthcare visit may facilitate interpreting STEs. Yet, the absence of an association between long-term measures of refill non-adherence with clinical and perceived DRMs suggest the need to enhance the knowledge of this association in clinical practice. In summary, this thesis shows a significant potential for improvements of medication use and outcomes.

Key words: Drug-related morbidity, medication adherence, inappropriate prescribing, elderly, drug utilisation, pharmacoepidemiology.

ISBN: 978-91-7519-025-9

ISSN: $0345-0082$

Linköping University Medical Dissertations No: 1469 


\section{SVENSK SAMMANFATTNING}

Felaktig användning av läkemedel, såsom vid förskrivning av olämpliga läkemedel eller vid bristande följsamhet till förskrivna läkemedel, kan medföra läkemedelsorsakad sjuklighet. Fler personer lever idag längre, och fler har kronisk sjukdom. Mot bakgrund av detta har problematiken med felaktig användning av läkemedel ökat i omfattning. Detta avhandlingsprojekt avser att studera potentiellt olämplig läkemedelsförskrivning hos äldre, följsamhetsproblem vid kronisk kombinationsmedicinering och relaterad läkemedelsorsakad sjuklighet.

I avhandlingen ingår fyra delstudier. Den första studien var en metaanalys av tidigare publicerade studier över förekomst av förhindringsbara biverkningar. Delstudie två och tre utgick från svenska patientjournaldata och registerdata för att studera potentiellt olämplig läkemedelsförskrivning och biverkningar hos äldre individer respektive följsamhetsproblem och otillräcklig effekt hos patienter med kronisk blodtrycksänkande medicinering. Den fjärde delstudien använde uppgifter från en nationell befolkningsenkät och registerdata för att studera uttagsmönster av läkemedel mot högt blodtryck, lipidrubbningar och diabetes, samt eventuella samband med självrapporterade biverkningar och otillräcklig effekt. Registerdata omfattade i de olika delstudierna exempelvis uppgifter om receptförskrivna läkemedel uthämtade på apotek, sociodemografiska faktorer och sjukvårdsförbrukning.

Cirka hälften av de biverkningar som identifierades hos patienter i både öppenvård och inom den slutna vården var möjliga att förhindra utifrån tidigare publicerade data. Svenska registerdata över läkemedelsuttag visade att knappt hälften av äldre patienter hade en potentiell olämplig läkemedelsförskrivning under en sex månaders period. I kombination med uppgifter från patientjournaler visade sig att en sådan förskrivning orsakade en knapp tredjedel av alla biverkningar. Äldre med potentiell olämplig läkemedelsförskrivning hade också en högre risk för biverkningar jämfört med individer utan en sådan förskrivning. Bristande följsamhet till läkemedel, såväl för enskilda läkemedel som kombinationer av läkemedel, var vanlig vid långtidsbehandling. Det fanns ett samband mellan låg ålder respektive låg inkomst och bristande följsamhet till ett enskilt läkemedel, medan behov av specialistvård, användning av flera läkemedel, ny användning uppvisade ett samband med bristande följsamhet till hela läkemedelsbehandlingsregimen. Bristande följsamhet till enskilt läkemedel sista månaden innan ett vårdbesök ökade risken för 
otillräcklig effekt men långtidsmått på bristande följsamhet var inte associerat med otillräcklig effekt eller annan läkemedelsrelaterad sjuklighet utifrån kliniska eller självrapporterade data.

Avhandlingsprojektet visar att felaktig användning av läkemedel är en viktig orsak till biverkningar. Potentiellt olämplig läkemedelsförskrivning är vanlig hos äldre individer och är associerad med förekomst av biverkningar. Bristande följsamhet till läkemedelsordinationer vid kronisk sjukdom förekommer ofta, har ett särskilt mönster och har ett komplext samband med behandlingsutfall. Dessa resultat kan vara underlag för interventioner anpassade efter individens särdrag. Sammantaget pekar avhandlingsprojektet på att det finns betydande potential för förbättringar inom läkemedelsområdet.

ISBN: 978-91-7519-025-9

ISSN: $0345-0082$ 


\section{LIST OF PAPERS}

This thesis is based on the following studies, referred to in the text by their Roman numerals. The articles have been printed in the thesis with the permission of the publishers.

I. Hakkarainen $\mathrm{KM}^{*}$, Hedna $\mathrm{K}^{*}$, Petzold M, Hägg S. Percentage of patients with preventable adverse drug reactions and preventability of adverse drug reactions - A meta-analysis. PLoS ONE 2012;7(3):e33236

II. Hedna K, Hakkarainen KM, Gyllensten H, Jönsson AK, Petzold M, Hägg S. Potentially inappropriate prescribing and adverse drug reactions in the elderly: A population-based study. Eur J Clin Pharmacol 2015 [Epub ahead of print] doi: 10.1007/s00228-015-1950-8

III. Hedna K, Hakkarainen KM, Gyllensten H, Jönsson AK, Andersson Sundell K, Petzold M, Hägg S. Non-adherence to antihypertensive therapy and elevated blood pressure: Should we consider the use of multiple medications? PLoS ONE 2015;10(9):e0137451

IV. Hedna K; Hägg S, Andersson Sundell K, Petzold M, Hakkarainen KM. Refill adherence and self-reported adverse drug reactions and sub-therapeutic effects: A population-based study. Pharmacoepidemiol Drug Saf 2013;22(12):1317-25

\section{* Shared first authorship}




\section{TABLE OF CONTENTS}

ABBREVIATIONS …………………................................................................ XIII

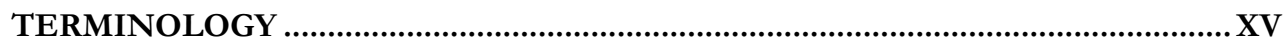

INTRODUCTION …………………..................................................................

Drug-related morbidities ...................................................................................................17

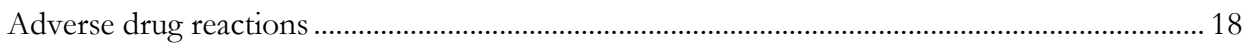

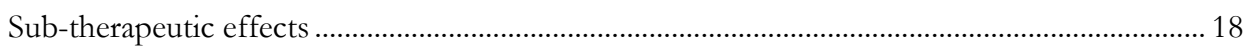

Inappropriate use of medications ...............................................................................19

Inappropriate use of medications and preventable drug-related morbidities................................ 20

Inappropriate prescribing in the elderly ...................................................................................... 21

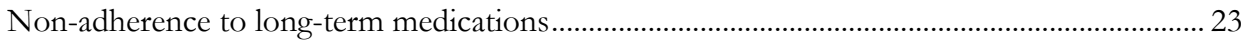

Rational of the thesis ...................................................................................................27

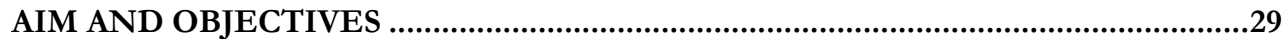

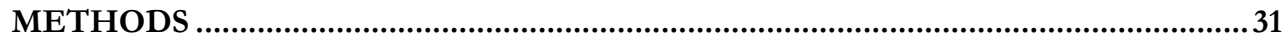

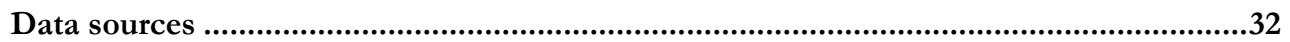

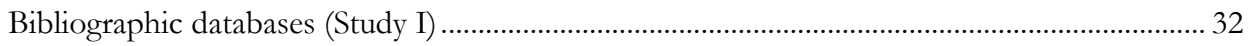

National population registers (Studies II-IV) ........................................................................... 32

Regional depository on patient healthcare (Studies III-IV) ........................................................... 32

Study designs and study populations ................................................................................33

Meta-analysis (Study I) ..................................................................................................... 33

Retrospective medical record studies (Studies II and III) ............................................................ 33

Cross-sectional survey to the general adult population (Study IV) ............................................... 33

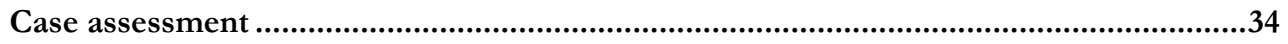

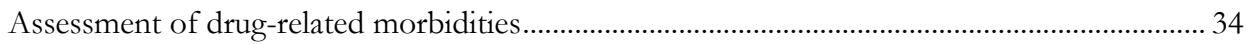

Assessment of inappropriate use of medications ………………………………………………….. 35

Statistical analysis ........................................................................................................

Ethical considerations ….............................................................................................38

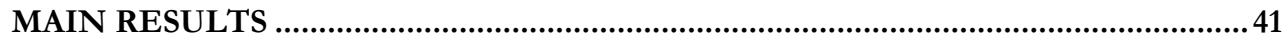

Preventable adverse drug reactions in healthcare settings (Study I)...................................41

Potentially inappropriate prescribing and adverse drug reactions in the elderly (Study

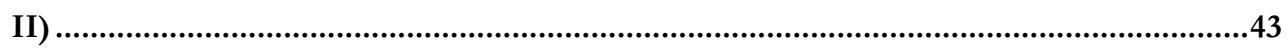

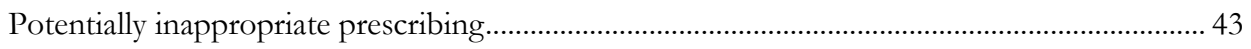


Potentially inappropriate prescribing and adverse drug reactions. 43

Non-adherence to long-term medications and related morbidities (Studies III and IV).44

Non-adherence to long-term medications 44

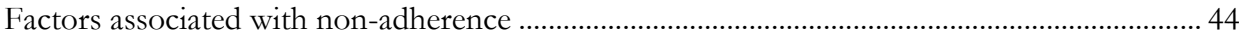

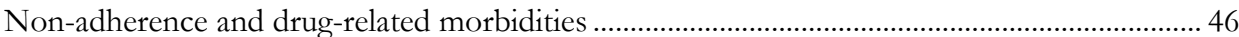

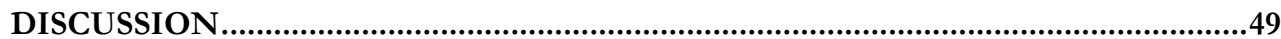

Preventable adverse drug reactions in healthcare settings .........................................49

Potentially inappropriate prescribing and adverse drug reactions in the elderly ..............50

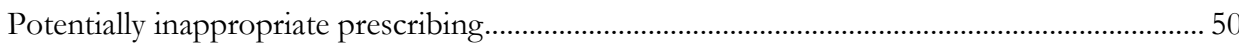

Potentially inappropriate prescribing and adverse drug reactions................................................... 51

Non-adherence to long-term medications and related morbidities ..................................54

Non-adherence to long-term medications............................................................................................ 54

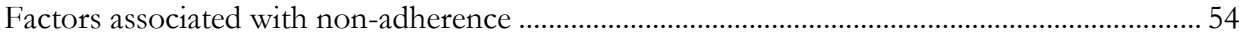

Non-adherence and drug-related morbidities .................................................................................. 55

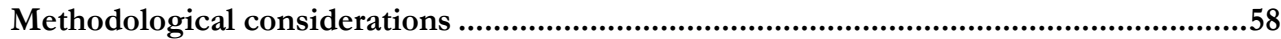

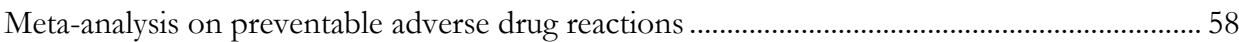

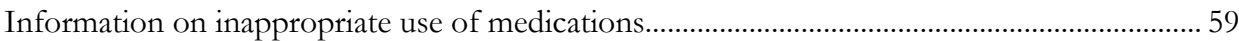

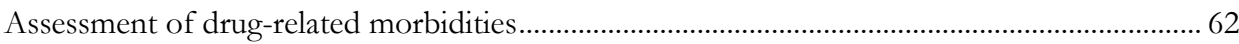

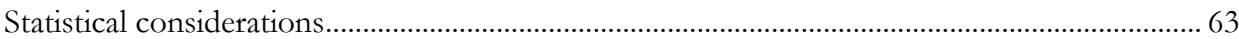

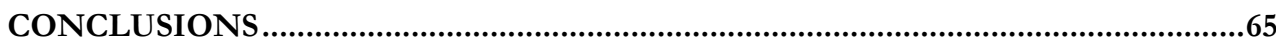

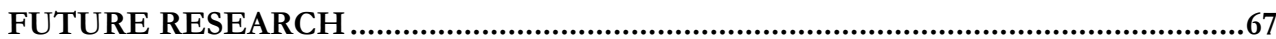

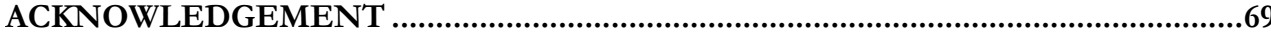

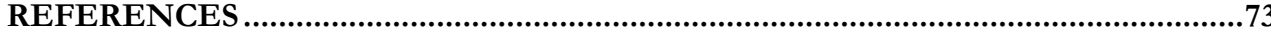

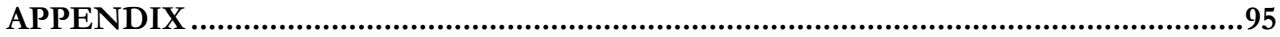




\section{ABBREVIATIONS}

$\begin{array}{ll}\text { ADR } & \text { Adverse drug reaction } \\ \text { ATC } & \text { Anatomical Therapeutic Chemical Classification System } \\ \text { BP } & \text { Blood pressure } \\ \text { CI } & \text { Confidence interval } \\ \text { CINAHL } & \text { Cumulative Index to Nursing and Allied Health Literature } \\ \text { CMA } & \text { Continuous medication acquisition } \\ \text { DRG } & \text { Diagnosis-related group } \\ \text { DRM } & \text { Drug-related morbidity } \\ \text { EMBASE } & \text { Excerpta Medica Database } \\ \text { EUR } & \text { Euro } \\ \text { ICD } & \text { International Classification of Diseases } \\ \text { IPA } & \text { International Pharmaceutical Abstract } \\ \text { LISA } & \text { Longitudinal integration database for health insurance and labour market studies } \\ \text { MedDRA } & \text { Medical Dictionary for Regulatory Activities } \\ \text { MEDLINE } & \text { Medical Literature Analysis and Retrieval System Online } \\ \text { MeSH } & \text { Medical Subject Heading } \\ \text { NSAID } & \text { Non-steroidal anti-inflammatory drug } \\ \text { OR } & \text { Odds ratio } \\ \text { OTC } & \text { Over-the-counter } \\ \text { PADR } & \text { Preventable adverse drug reaction } \\ \text { PDC } & \text { Proportion of days covered } \\ \text { PDRM } & \text { Preventable drug-related morbidity } \\ \text { PIN } & \text { Personal identity number } \\ \text { PIPs } & \text { Potentially inappropriate prescription } \\ \text { PsycINFO } & \text { Abstract database of psychological literature } \\ \text { Q } & \text { Quartile } \\ \text { SCB } & \text { Statistics Sweden } \\ \text { SD } & \text { Standard deviation } \\ \text { SPDR } & \text { Swedish Prescribed Drug Register } \\ \text { STE } & \text { Sub-therapeutic effect of drug therapy } \\ \text { STOPP } & \text { Screening Tool of Older Persons' potentially inappropriate Prescriptions } \\ \text { VDL } & \text { Care Data Warehouse of Östergötland } \\ \text { WHO } & \text { World Health Organization } \\ & \end{array}$




\section{TERMINOLOGY}

Adherence to prescribed medication

Adverse drug reaction

Drug-related morbidity

Potentially inappropriate prescription

Preventable drug-related morbidity

Sub-therapeutic effect
The extent to which an individual acts in accordance with the prescribed dosing interval and dose of prescribed medications (1).

Response to a drug which is noxious and unintended, and which occurs at doses normally used in man for the prophylaxis, diagnosis, or therapy of disease, or for the modification of physiological function (2).

Failure of a therapeutic agent to produce the intended therapeutic outcome and the manifestation of unresolved drug-related problems (3).

Prescription that introduces a significant risk of an adverse drugrelated event when there is evidence for an equally or more effective alternative medication (4).

Drug-related morbidity resulting from an inappropriate use of medication at any stage of the use process, reaching the patient and causing any degree of harm.

A failure to accomplish the goals of treatment resulting from inadequate or inappropriate drug therapy and not related to the natural progression of disease (5). 


\section{INTRODUCTION}

Today, medications are the most common therapy in healthcare. More than half of the adult population, and three out of four individuals aged 65 years and older, use at least one prescribed medication, mainly to treat chronic conditions (6-10). Advances in medication therapies have resulted in major improvements in the prevention and treatment of many diseases $(11,12)$. In order to achieve optimal health outcomes and minimise adverse outcomes, medications should be prescribed and used in accordance with the best understanding of their appropriateness for the particular patient. Yet, drug-related morbidities (DRMs) are among the most common adverse outcomes in healthcare (13-16).

\section{Drug-related morbidities}

Drug-related morbidities, also referred to as adverse drug events (ADEs), may be defined as " $a$ failure of a therapentic agent to produce the intended therapeutic outcome" and "the manifestation of unresolved drug-related problems" (3). Even though definitions of DRMs vary in the literature (17-19), they include both outcomes below or beyond the optimal medication intended outcomes (20). Outcomes below the optimal medication intended outcomes have been categorised in subtherapeutic effects (STEs) (termed also therapeutic failures), and morbidities due to drug-related untreated indications (21-23). Outcomes beyond the optimal medication intended outcomes may be defined as new medical problems produced by the medication, and categorised in adverse drug reactions (ADRs), drug dependence and abuse, and intoxications by overdose (21). Previous studies on DRMs, mainly conducted in emergency and inpatient settings, have found that ADRs and STEs are the most common DRMs (22-27). DRMs have been associated with worsening of quality of life of patients (28-30), mortality (31-33), and increased costs for healthcare and society $(20,34,35)$.

DRMs are common in both inpatient and outpatient care (21,36-38). Previous systematic reviews have reported that nearly $5 \%$ of patients, at mean or median, experience a DRM at the time of admission or during hospitalisation $(39,40)$, making DRMs one of the most common types of harm experienced by inpatients $(13,16)$. Patients in other care settings, including ambulatory and primary care have been estimated to experience DRMs at even higher rates $(21,38)$. A previous systematic review and a large population-based study have estimated that about $13 \%$ of ambulatory patients, and across care settings experience a DRM $(21,38)$. However, the frequency of DRMs has varied widely from $0.2 \%$ to $65 \%$ in individual studies $(38,40,41)$, due to differing study designs 
and settings, study populations, and detection methods of DRMs (39, 42). Moreover, DRMs are found more often among the elderly and persons with multiple medications $(38,43-45)$.

\section{Adverse drug reactions}

The most recognised category of DRMs is ADRs. The World Health Organization (WHO) defines an ADR as "a response to a drug which is noxious and unintended, and which occurs at doses normally used in man for the prophylaxis, diagnosis, or therapy of disease, or for the modification of physiological function" (2). While ADRs have been considered by some researchers as not preventable as they refer to the drug product itself (17), it is now widely recognised that ADRs may result from inappropriate use of medications (IUM), such as inappropriate prescribing of inappropriate medication, or inappropriate dose, inappropriate monitoring or drug interactions (46-49), and are thus considered as potentially preventable ${ }^{1}$. It should be noted that susceptibility to ADRs is greatly increasing in patients with multiple morbidities, taking multiple medications, and with renal and hepatic failures such as the elderly $(43,50-52)$.

Systematic reviews have estimated that 3-6\% of hospital admissions are caused by ADRs $(32,39$, $43,53,54)$. However, none of them have investigated the proportion of patients who experienced an ADR due to IUM, termed as "preventable ADR" (PADR) or the preventability of ADRs in different healthcare settings. In fact, reviews have either reported PADRs as part of all PDRMs, have not used meta-analyses techniques to pool the results $(47,54)$, or have not applied standardised definition for ADRs and clear criteria for preventability. Since ADRs are common DRMs and the most consistently defined, estimating the burden of PADRs in different healthcare settings is important prior to analysing contributing factors and to allocating resources to prevent them.

\section{Sub-therapeutic effects}

Sub-therapeutic effects (termed also as therapeutic failures) have been defined as "a failure to accomplish the goals of treatment resulting from inadequate or inappropriate drug therapy and not related to the natural progression of disease" (5). STE is a complex concept and can be due to multiple factors such as under-prescribing of the appropriate therapy (too low dose, or too short period), or patients' under-use of prescribed medications because of non-adherence and genetic, physiological and

\footnotetext{
${ }^{1}$ IUMs are described in more detail under the sections "Inappropriate use of medications"
} 
environmental factors affecting pharmacokinetics and pharmacodynamics (55-59). An example of an STE is elevated blood pressure (BP) in a patient who has been prescribed a dose of antihypertensive medications that is too low, or underuse of an appropriate antihypertensive therapy because of the patient's non-adherence.

Studies on DRMs in hospital settings have reported that STEs occur in 1-9\% of admissions or emergency visits $(22,24,26,60)$. The WHO considers STEs of long-term therapies as a major public health problem, as chronic conditions are widespread and often inadequately controlled, despite the evidence of medication efficacy to control them $(61,62)$. Chronic conditions, such as cardiovascular diseases or their complications are the most common causes of death worldwide (63). Cardiovascular chronic conditions are called the "silent killers" (64), as a high proportion of treated patients have inadequately controlled conditions (such as elevated BP or hypercholesterolemia), and even a higher percentage are unaware of the symptoms of their uncontrolled condition (65-69). Although healthy behaviour is recognised to have an important role in managing non-communicable chronic diseases (70), adherence to long-term prescribed medications is considered a crucial factor in achieving the optimal outcomes of prescribed medications and preventing the complications of chronic conditions $(58,71-74)$.

\section{Inappropriate use of medications}

Appropriate use of medications implies that "the drug is appropriate for the patient's needs and administered in an individually adjusted dosage for an adequate period of time at the lowest cost to the patient and the community"

(75). An appropriate, safe and cost-effective medication treatment depends on appropriate care in each stage of the medication use process, including: diagnosing, prescribing, administering (by the caregiver or the patient), monitoring and patient understanding and adherence to the prescribed medication (76).

IUM may occur at any stage of the medication use process and is considered as a therapy care process failure $(76,77)$. It may be due to either a violation or a medication error. Errors are usually unintentional, while violations are deliberate deviations from safe and well established practices (78). The medication error has been defined as "a failure in the drug treatment process that leads, or has the potential to lead, to harm the patient."(17). An error may be an act of commission (doing the wrong thing) or an act of omission (failing to do the right thing) (76). Some examples of IUM include wrong medication or dosage prescribed, wrong dosage administered for a prescribed medication, or failure to give (by the healthcare giver) or to take (by the patient) a medication. 


\section{Inappropriate use of medications and preventable drug-related morbidities}

When IUM leads to a DRM, the DRM is considered preventable (Figure 1). Thus, IUM is recognised as a major cause of preventable drug-related morbidities (PDRMs) (36, 45), and wastage of scarce resources $(79,80)$, and requires coordinated cross-system efforts to reduce preventable harms $(76,77)$. Nonetheless, there is also a need to identify and study the stage of the medication use process at which most IUM occurs in order to target interventions (81). The evidence is accumulating from studies on recurring causes of PDRMs that could become targets for preventive interventions. Previous systematic reviews have reported that most PDRMs have been associated with one or more instances of inappropriate prescribing or patient non-adherence to prescribed medications $(36,45,82-84)$.

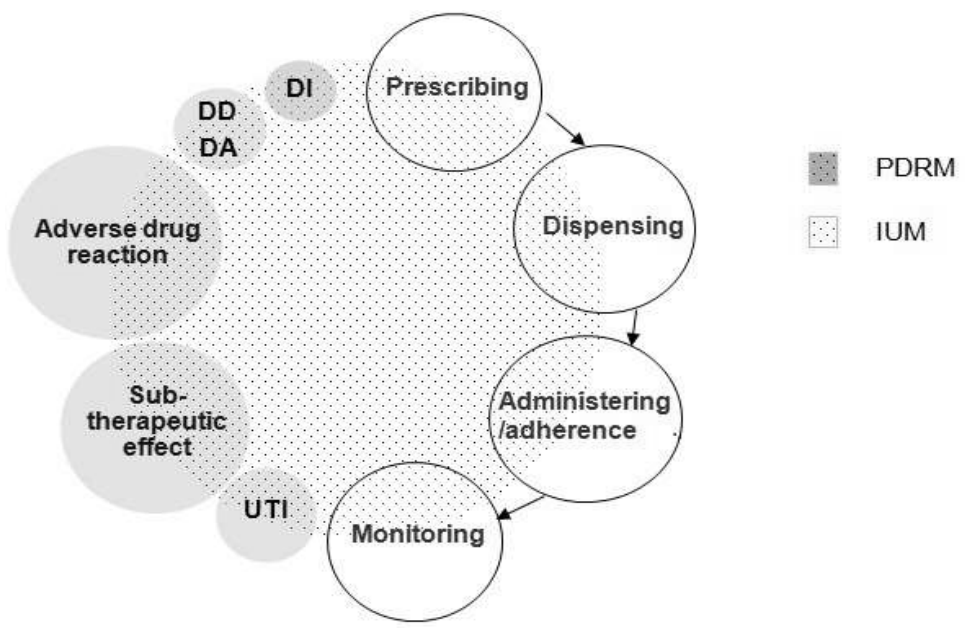

DA: Drug abuse; DD: Drug dependence; DI: Drug intoxication by overdose; IUM: Inappropriate use of medications; PDRM: Preventable drug-related morbidity, UTI: Morbidity due to drug-related untreated indication

Figure 1. Association between inappropriate use of medications and preventable drugrelated morbidities

Since the prescription of a medication represents the most common healthcare intervention, targeting research into the inappropriate use of prescribed medications, and thereby preventing DRMs, represents an important way of improving both the safety and quality of healthcare (85). Reducing PDRMs has a potentially positive impact on the quality of life of patients, the safety of healthcare, and the efficient use of healthcare resources $(3,85,86)$. The first step is to measure the magnitude of the most common types of DRMs due to IUM in order to develop interventions to improve the appropriate use of prescribed medications (81). 
Preventing DRMs has attracted considerable attention since the publication by the Institute of Medicine in the United States of the report "To Err Is Human: Building a Safer Health System" in the late 1990s (87). This publication reported that over 100000 US hospital patients experienced preventable deaths due to medical errors, with medication errors being the leading cause of these preventable deaths. Improving patient safety and in particular medication safety is now firmly on the health policy agenda of the WHO (88), international (89), and national authorities (90-92).

Numerous studies have been conducted in the recent years, mainly in hospital settings, to estimate the prevalence and causes of DRMs resulting from IUM, and thus considered potentially preventable $(36,37,82)$. It is estimated that about $20-60 \%$ of DRMs are potentially preventable, although estimates vary from $11 \%$ to $90 \%$ in individual studies $(36,37,41,93)$. However, despite a large proportion of patients have mainly primary care encounters, research on IUM and related DRMs in primary care or in the general population is less extensive.

\section{Inappropriate prescribing in the elderly}

Inappropriate prescribing may be defined as "the prescription that introduces a significant risk of an adverse drug-related event when there is evidence for an equally or more effective alternative medication" (4). Inappropriate prescribing includes: (i) the omission of prescription of a medication that is clinically indicated (underprescribing), (ii) the prescription of a medication without a clinical indication (overprescribing), and (iii) the prescription of a medication that increases the risk of a DRM, such as inappropriate dose or inappropriate period, or medication that increases the risk of drug-drug or drug-disease interaction (misprescribing) (94).

Inappropriate prescribing is a significant cause of DRMs (95-97), hospitalisation and mortality (98, 99). It has therefore become an important public health issue as it represents a clinical and economic burden to patients and society $(79,80,100)$. Inappropriate prescribing in the elderly is highly prevalent, ranging from $12-62 \%$, depending on the study population and the method used to assess the appropriateness of prescribing, and has been higher among the elderly in nursing homes $(94,101)$. With the global ageing population, improving the quality and safety of healthcare of the elderly, including improving prescribing, poses a global challenge.

Assessing the quality of prescribing in the elderly is complex. Many factors contribute to this complexity, including (i) age-related physiological changes, such as hepatic and kidney failures and increased body fat, which influence pharmacokinetics and pharmacodynamics and may lead to increased sensitivity to medication effects (102); (ii) co-morbid conditions, multidrug therapy and 
care from several healthcare clinicians who may not coordinate medication treatment (103); (iii) limited availability and access to appropriate evidence regarding medication effectiveness and safety in older and frail patients $(104,105)$.

Since the 1990's, several indicators have been developed to assess the appropriateness of prescribing in the elderly (106). These indicators may be categorised in implicit criteria (judgementbased), and explicit criteria (criterion-based) (107). Implicit criteria rely on the clinician's judgement applied to patient individual medications. They may provide valid information on the prescriptions, but they are time-consuming with low inter-rater reliability which hinders their use for large studies and for comparison between studies (107). Therefore, explicit criteria are used in this thesis.

\section{Explicit potentially inappropriate prescriptions criteria}

Explicit potentially inappropriate prescriptions (PIPs) criteria are commonly used to assess the quality of prescribing among the elderly (108-111). They are developed from literature reviews, experts' opinions and consensus techniques and are based on choice of medication, dose, druginteraction and duration of medication utilisation (112).

The Beers criteria, developed primarily in North America, are among the first and most known criteria. They were developed in the 1990's (113), and have been updated several times, most recently in 2012 (114). They originally included a list of medications to avoid in the elderly in nursing homes (113), but were then updated to include community-dwelling elderly (114). However, the previous versions of Beers criteria have been criticised because of the lack of a reproducible association with ADRs and adverse health outcomes, and the inclusion of medication as being absolutely contra-indicated irrespective of the diagnosis (115-118). Numerous nationally adapted criteria have been developed and partially overlap (108-111). The majority of explicit PIPs criteria focus on misprescribing and overprescribing, with only few of them considering underprescribing of indicated medications (110). Therefore, in studies, "inappropriate prescribing" often refers to overprescribing and misprescribing. An evidence-based set of PIPs criteria, called STOPP/START (Screening Tool of Older Person's Prescriptions/Screening Tool to Alert doctors to Right Treatment) have been developed in recent years (119). These criteria include the misprescribing, overprescribing (STOPP criteria) and underprescribing (START criteria). Compared to other criteria, they consider the inappropriateness of prescribed medications within specific clinical contexts. Thus, their application may be more suitable in the clinical context for a comprehensive medication review of individual patients. They have been used by researchers in 
different jurisdictions in Europe and elsewhere to evaluate the quality of prescribing in the elderly (120-124), and have been endorsed as being an appropriate choice for evaluating the quality of prescribing of elderly patients with multiple chronic conditions $(125,126)$.

For an instrument to be valid, it should demonstrate evidence of causal links with important adverse outcomes. Yet, the majority of research on PIPs has focused on estimating the prevalence and investigating the risk factors for PIPs (101, 123, 127-130), or the association between PIPs and serious adverse health outcomes, such as hospitalisations and death $(98,99)$. Although nonserious ADRs may be more tolerable than the severe symptoms associated with the underlying condition, they should still be considered, as they are associated with worsening quality of life, and increase use of healthcare $(28,30,34)$, especially if safer and more tolerated therapeutic alternatives exist. The few studies that have investigated the association between PIPs and ADRs have been mainly conducted in hospital settings and nursing homes, and only a few of them found a significant association between PIPs and ADRs (95, 117, 131-133). Since the elderly mainly use primary care, there is a need to explore the evidence of the association between PIPs and ADRs in all healthcare settings, including primary care settings.

\section{Non-adherence to long-term medications}

Adherence to prescribed medications has been defined in numerous ways but is often understood as the extent to which an individual acts in accordance with the prescribed dosing interval and dose of prescribed medications (1). The term adherence is preferred to the term "compliance", which suggests that the patient passively follows the doctor's orders whereas the term adherence emphasises patient and clinician collaboration in decisions $(1,134,135)$. Medication adherence may be divided into three components: (i) initiation (when the patient starts with the prescribed pharmacotherapy); (ii) implementation (defined as the agreement between the patient's real medication-taking behaviour and prescribed medication dosing regimen), and (iii) discontinuation, which marks the end of therapy, when no more doses are taken (1).

Non-adherence to prescribed medication is considered an important cause of STEs of prescribed medications $(55,56,58)$, and a major cause of morbidity $(72-74,136-141)$ and increased healthcare costs $(137,142,143)$. The prevalence of non-adherence has varied widely between studies, depending on multiple factors, such as the characteristics of the disease and the therapy (144). For example, non-adherence has been found to be higher for long-term than short term therapies (145), for preventive than curative therapies, and for asymptomatic conditions, such as hypertension $(145,146)$. The WHO estimates that up to $50 \%$ of patients with chronic conditions 
have inadequate adherence to their long-term medications (58). While patients were previously blamed for non-adherence to prescribed medications, non-adherence is now considered as a fundamental failure of the healthcare system (62). The seriousness of this problem has prompted the WHO to quote the statement that "Increasing the effectiveness of adherence interventions may have a far greater impact on the bealth of the population than any improvement in specific medical treatments" (58).

Different methods have been developed to measure adherence to prescribed medications in clinical practice, and may be categorised in direct and indirect methods (147). Direct methods include: surveying patients, directly observing medication taking, and measuring drug or metabolite blood levels. Indirect methods include: self-reports, pill counts, electronic medication monitors, and pharmacy refill rates (refill adherence). Direct methods, in particular measuring drug blood levels, are considered to be more robust than indirect methods in measuring adherence (148), but they are costly and impractical for routine clinical use and for large epidemiological studies. Thus, indirect methods are more widely used to measure adherence. Self-report measures of adherence have been found associated with health outcomes, but are known to overestimate adherence, as patients may report an overly optimistic estimation of adherence (149). Pill counts are frequently used in randomised controlled clinical trials. However, there is a risk of data manipulation by patients through pill dumping (150).

Refill adherence is one of the most used methods to measure adherence, and has been correlated with other measures of adherence (151). The act of refilling prescribed medications and the frequency of medication refills reflect different aspects of a patient's adherence behaviour, and can be divided into adequate refill adherence, undersupply and oversupply (152). Refill adherence is only considered as a proxy measure of adherence if patients obtain their medications within a closed pharmacy system, such as in countries with universal medication coverage (147). Because of the increasing use of refill data to measure adherence, different methods have been developed, essentially defined by the number of doses dispensed in relation to a dispensing period. The cutoff of $80 \%$ of the time with medications available is generally used to define adherence (153-156).

A large proportion of patients with chronic conditions commonly receive multiple medications to treat a single disease $(157,158)$. Therefore, enhancing the knowledge of adherence to a multidrug therapy is of clinical significance in order to determine whether a patient is non-adherent to any medications in the therapy regimen (i.e. complete non-adherence), or whether he has problems to adhere to a complex multidrug therapy (non-adherence to the full multidrug therapy). Yet, the majority of studies on refill adherence have only included patients prescribed one medication for 
a single disease, or have measured the adherence to only one medication or therapeutic class (140, 159-162). Therefore, there has been a call in recent years to better understand the measures of refill adherence in situations where patients are prescribed multiple medications to treat a single disease $(155,156,163)$, in order to better understand patient behaviour toward a multidrug therapy.

Furthermore, the WHO has categorised factors associated with non-adherence to long-term therapy into five groups that include patient, condition, therapy, socioeconomic, and health system-related factors (58) (Figure 2). Some factors found associated with non-adherence include younger age (164), presence of comorbidities (165), lower socio-economic status (166), the use of multiple medications (163), and being a new user (167). Yet, previous research has not differentiated between factors associated with non-adherence to any medication in the therapy, and with non-adherence to the full multidrug therapy, even though they may differ for the two distinct types of non-adherence. Hence, a better understanding of the association of these factors with the two distinct types of non-adherence to a multidrug therapy is important in order to tailor interventions to improve adherence to patient needs.

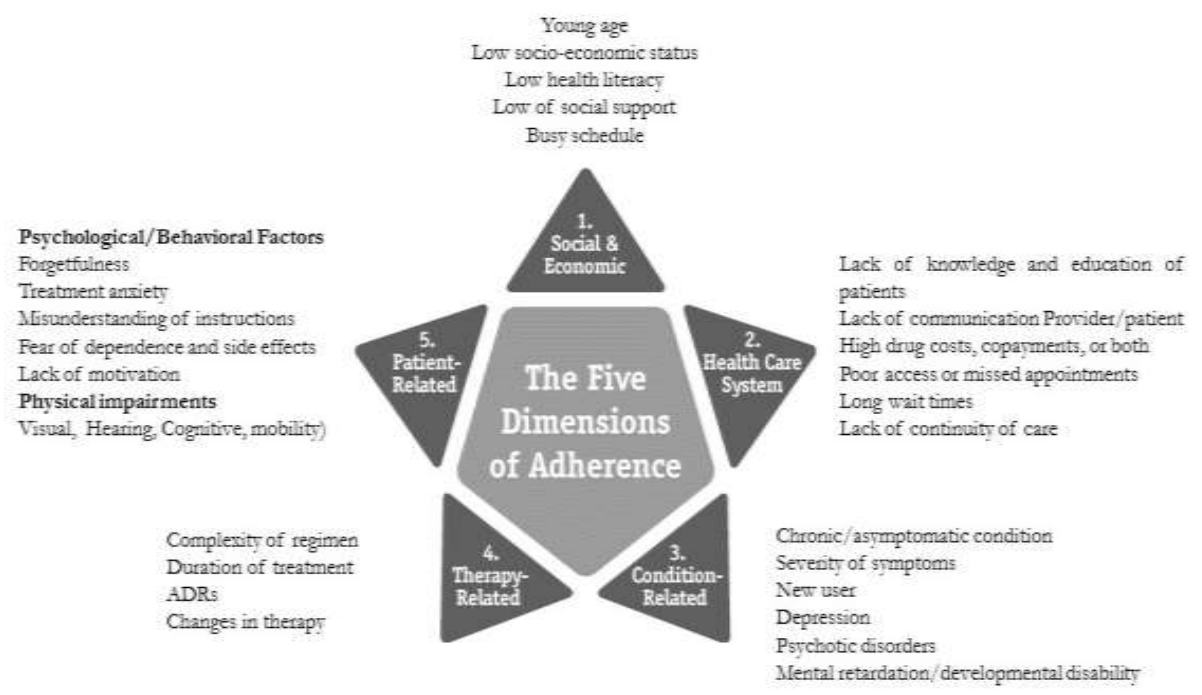

Figure 2. Examples of factors associated with non-adherence $(58,74,147)$

Most studies on refill-adherence do not consider the aspect when patients accumulate oversupplies of their long-term medications. However, refilling large amounts of medications may make often complex therapy regimens more difficult to follow. Patients, in particular the elderly with multiple medications, may be confused about which medications they are supposed to take. They may for example unintentionally overuse the same medication $(168,169)$, which increases the risk to 
experience ADRs. Previous studies have found that oversupply of medications was found in up to $53 \%$ of patients taking antidiabetics $(152,170-173)$, up to $52 \%$ with antihypertensive medications $(152,170,174,175)$, and up to $35 \%$ with lipid lowering medications $(152,170)$. Clinical data suggest that patients with more than $120 \%$ of their needed medication supplies use more healthcare resources $(142,174,176,177)$, and are more likely to be hospitalised $(174,177$, 178). However, the association between refill behaviour and experienced DRMs has not been investigated. Understanding the association between patients' medication refill behaviour, including the oversupply and their perceived DRMs is important for improving the management and outcomes of medication therapies. This is of particular importance for self-managed prescribed medications of asymptomatic chronic conditions with repeat refill prescribing and limited contact with caregivers (179). 


\section{Rational of the thesis}

Improvements in living conditions and healthcare have led to important progress in the survival of global population. Persons aged 65 years and older are the fastest growing category of the population all over the world $(180,181)$. In developed countries, a century ago, one individual in 20 was aged 65 years and older, in 2013 one in six, and this demographic is expected to comprise nearly $30 \%$ of the overall population by 2050 (181). In Sweden, the number of persons over 65 years is estimated to increase by $48 \%$ between the years 2015 and 2050, while the corresponding increase for the entire population is expected at 25\% (182). About two-thirds of the elderly are estimated to have two or more chronic conditions $(9,183)$. Up to three out of four elderly are regularly prescribed one or more medication (6-9), and up to two thirds have polypharmacy (five or more medications) $(9,184,185)$. Moreover, people over 65 years account for three times as many healthcare expenditures than those individuals younger than 65 years (186), and experience more DRMs, often considered as preventable (43, 50-52). Therefore, the increasing number of elderly people in the society will pose challenges for healthcare systems.

The twentieth century also witnessed a global rise in chronic conditions (62). In 2006, up to $40 \%$ of the European population aged 15 years and older had a chronic health problem (66). The WHO estimates that globally, chronic conditions (cardiovascular diseases, diabetes, and other conditions of ageing) will represent around 65\% of deaths annually by 2030 (62). Around 75\% of healthcare costs are related to chronic conditions, and the economic impact extends beyond the healthcare system (187). Despite the availability of effective treatments, studies have shown that up to half of patients with chronic conditions do not achieve optimal treatment outcomes, and non-adherence to prescribed medications has been identified as a major barrier (58).

As shown from this introduction, preventing DRMs due to IUM has gained considerable attention since the 1990's. Therefore, summarising the previous evidence on the burden of the most recognised category of PDRMs - PADRs - will allow to better estimate the association between IUM and PADRs in different healthcare settings. Furthermore, with the ageing population and the increase burden of chronic conditions, a better understanding of inappropriate prescribing in the elderly and non-adherence to long-term therapies and their association with DRMs in the general population is essential. Lastly, investigating the relationship between refill behaviour of long-term medications and perceived DRMs may contribute to improving the self-management of long-term medications. 


\section{AIM AND OBJECTIVES}

The overall aim of this thesis is to estimate the burden of two types of inappropriate use of medications, potentially inappropriate prescriptions in the elderly and non-adherence to long-term medications among adults across care settings, and to investigate how inappropriate use of medications is associated to drug-related morbidities.

Largely prescribed long-term therapies were used as a model to study non-adherence, which may be applied to other long-term therapies.

Specific objectives of studies are described in Table 1.

Table 1. The specific objectives of the individual studies

\section{Study Main objective}

I To estimate the percentage of adult patients with preventable ADRs and the preventability of ADRs in healthcare settings.

II To determine the prevalence of PIPs in the Swedish elderly general population, including all care settings and to study the association between PIPs and the occurrence of ADRs.

III To identify factors associated with non-adherence to antihypertensive therapy considering the use of multiple medications, and to analyse the association between non-adherence and elevated BP.

IV To assess the refill adherence for dispensed oral long-term medications* in a random sample of the general adult population in Sweden and to investigate whether the percentages of self-reported ADRs and STEs differed for medications with adequate refill adherence, oversupply, and undersupply.

ADR: Adverse drug reaction; BP: Blood pressure; PIPs: Potentially inappropriate prescriptions; STE: Sub-therapeutic effect of drug therapy.

* Antihypertensive, lipid lowering and oral antidiabetic medications 


\section{METHODS}

Table 2 summarises the study designs, data sources and outcomes measured in studies I-IV of this thesis.

Table 2. Overview of studies in this thesis

\begin{tabular}{|c|c|c|c|c|c|c|}
\hline Study & Design & Data source & $\begin{array}{l}\text { Study } \\
\text { period }\end{array}$ & Study population & $\begin{array}{l}\text { Outcomes and } \\
\text { studied } \\
\text { associations }\end{array}$ & $\begin{array}{l}\text { Statistical } \\
\text { analysis }\end{array}$ \\
\hline I & Meta-analysis & $\begin{array}{l}\text { Citations in } \\
\text { seven } \\
\text { bibliographic } \\
\text { databases } \\
(\mathrm{N}=5770)\end{array}$ & -2010 & $\begin{array}{l}\text { Original research: } \\
\text { Sixteen studies with } \\
\text { outpatients } \\
(n=48797) \text { and eight } \\
\text { studies with } \\
\text { inpatients }(n=24128)\end{array}$ & $\begin{array}{l}\text { PADRs among } \\
\text { healthcare visits }\end{array}$ & $\begin{array}{l}\text { Meta- } \\
\text { analysis }\end{array}$ \\
\hline II & $\begin{array}{l}\text { Retrospective } \\
\text { medical } \\
\text { record study }\end{array}$ & $\begin{array}{l}\text { Medical } \\
\text { records, Care } \\
\text { Data } \\
\text { Warehouse of } \\
\text { Östergötland, } \\
\text { Swedish } \\
\text { Prescribed } \\
\text { Drug Register, } \\
\text { LISA database } \\
(\mathrm{N}=5025)\end{array}$ & 2008 & $\begin{array}{l}\text { Elderly ( } \geq 65 \text { years) } \\
\text { from a random } \\
\text { sample of general } \\
\text { population in the } \\
\text { county council of } \\
\text { Östergötland } \\
(\mathrm{n}=813)\end{array}$ & $\begin{array}{l}\text { Prevalence of PIPs } \\
\text { Association } \\
\text { between PIPs and } \\
\text { ADRs }\end{array}$ & $\begin{array}{l}\text { Descriptive } \\
\text { Multiple } \\
\text { logistic } \\
\text { regression }\end{array}$ \\
\hline III & $\begin{array}{l}\text { Retrospective } \\
\text { medical } \\
\text { record study }\end{array}$ & $\begin{array}{l}\text { Same as study } \\
\text { II }\end{array}$ & $\begin{array}{l}2007- \\
2008\end{array}$ & $\begin{array}{l}\text { Adults from a } \\
\text { random sample of } \\
\text { the general } \\
\text { population in the } \\
\text { county council of } \\
\text { Östergötland treated } \\
\text { for essential } \\
\text { hypertension } \\
(n=867)\end{array}$ & $\begin{array}{l}\text { Factors associated } \\
\text { with non- } \\
\text { adherence to } \\
\text { antihypertensive } \\
\text { therapy } \\
\text { Association } \\
\text { between non- } \\
\text { adherence to } \\
\text { antihypertensive } \\
\text { therapy and } \\
\text { elevated BP }\end{array}$ & $\begin{array}{l}\text { Descriptive } \\
\text { Multiple } \\
\text { logistic } \\
\text { regression }\end{array}$ \\
\hline IV & $\begin{array}{l}\text { Cross- } \\
\text { sectional } \\
\text { survey study }\end{array}$ & $\begin{array}{l}\text { Respondents to } \\
\text { postal } \\
\text { questionnaire, } \\
\text { LISA database, } \\
\text { Swedish } \\
\text { Prescribed } \\
\text { Drug Register } \\
(\mathrm{n}=7099)\end{array}$ & 2010 & $\begin{array}{l}\text { Respondents to the } \\
\text { survey who filled } \\
\text { antihypertensive, } \\
\text { lipid lowering or oral } \\
\text { antidiabetic } \\
\text { medications } \\
(n=1827)\end{array}$ & $\begin{array}{l}\text { Refill behaviour* } \\
\text { of prescribed } \\
\text { medications. } \\
\text { Association } \\
\text { between refill } \\
\text { behaviour and } \\
\text { perceived ADRs } \\
\text { and STEs }\end{array}$ & Descriptive \\
\hline
\end{tabular}

ADR: Adverse drug reaction; BP: Blood pressure; LISA: Longitudinal integration database for health insurance and labour market studies; PADR: Preventable adverse drug reaction; PIPs: Potentially inappropriate prescriptions; STE: Sub-therapeutic effect of drug therapy.

*Undersupply, adequate supply and oversupply of antihypertensive, lipid lowering and oral antidiabetic medications. 


\section{Data sources}

\section{Bibliographic databases (Study I)}

Seven bibliographic databases commonly used in systematic reviews in healthcare were searched: the Cochrane database of systematic reviews, the Cumulative Index to Nursing and Allied Health Literature (CINAHL), the Excerpta Medica Database (EMBASE), the International Pharmaceutical Abstract (IPA), the Medical Literature Analysis and Retrieval System Online (Medline), the Abstract database of psychological literature (PsycINFO) and Web of Science. The citations are organised according to index terms which are commonly used for bibliographic search (188).

\section{National population registers (Studies II-IV)}

The Total Population Register and the longitudinal integration database for health insurance and labour market studies (LISA) databases are held by Statistics Sweden (SCB). The Total Population register includes demographic variables (189), and the unique personal identity number (PIN) which permits data linkage between the registers (190). The LISA database covers all Swedish residents aged 16 years or more, and includes demographics and socioeconomic factors (191).

The Swedish Prescribed Drug Register (SPDR) is held by the National Board of Health and Welfare (192). The SPDR covers all dispensed prescribed medications for outpatient use since 2005. It contains information on the name of the dispensed medications, the Anatomical Therapeutic Chemical classification system (ATC code), the amount of medications dispensed, the prescribed daily dose given in free text, and the date of dispensing (192). The SPDR excludes medications bought over-the-counter (OTC), prescribed medications administered in hospitals, and emergency medications in residential care and nursing homes.

The National Patient Register is held by the National Board of Health and Welfare. It includes all in-patient care in Sweden since 1987. It includes information on time of hospitalisation and hospital discharge and diagnoses classified according to the International Classification of Diseases, 10th revision (ICD-10) (193).

\section{Regional depository on patient healthcare (Studies III-IV)}

The Care Data Warehouse of Östergötland "Vårddatalagret" (VDL) contains administrative data on all healthcare resources provided by the county (194). All inpatient and public outpatient care, and private outpatient care reimbursed by the county are recorded in VDL, which is considered to 
have a full coverage. An electronic medical record database stores all inpatient and public outpatient medical records.

\section{Study designs and study populations}

\section{Meta-analysis (Study I)}

The seven bibliographic databases (Cochrane, CINAHL, EMBASE, IPA, Medline, PsycINFO and Web of Science) were searched in September 2010, using the databases' index terms and other commonly used terminology on DRMs and preventability in titles and abstracts of the citations.

References of included original articles and previous relevant reviews were retrieved to identify additional relevant articles and consider their inclusion. In order to avoid inconsistent estimates and to decrease the heterogeneity between studies, ADRs had to be defined according to the WHO (2), or to a similar definition (48). Outcome measures of the included studies had to include the percentage of patients with preventable ADRs or the assessment of their preventability. Data on study characteristics, ADRs, PADRs, causes of PADRs, and data to calculate the preventability of ADRs were extracted.

\section{Retrospective medical record studies (Studies II and III)}

A random sample of 5025 adult residents in the county council of Östergötland ( $\geq 18$ years on $31^{\text {st }}$ December 2007) was drawn from the Total Population Register. The county was selected due to representative demographic distribution of the general Swedish population and the availability of electronic medical records.

In study II, a retrospective cohort study was conducted using the medical and administrative data of patients older than 65 years, who had at least one healthcare encounter (nurse or physician, outpatient or inpatient, primary or specialised) over a 3-month period in 2008.

In study III, persons with essential hypertension, who filled any antihypertensive medication in 2007, defined by corresponding ATC codes from the SPDR, were identified through the diagnosis of essential hypertension from their medical records (ICD-10 code: I10), or indication of hypertension from their refill data.

\section{Cross-sectional survey to the general adult population (Study IV)}

A cross-sectional population-based survey was mailed in 2010 to a random sample of 13921 residents aged 18 years and older to identify perceived DRMs (195). The sample was drawn from 
the Swedish Total Population Register. The survey and its introductory letter were mailed by SCB in October 2010. Two reminders with a re-posted survey were posted in November 2010 and January 2011.

In total 7099 persons (51\%) returned the survey to SCB which linked the survey responses to data on the respondents' refilled medications from SPDR, and data on age and sex from the LISA database. Respondents who refilled antihypertensive, oral antidiabetic or lipid lowering medications in the period of ten months prior answering the survey were considered to be included in the study.

\section{Case assessment}

\section{Assessment of drug-related morbidities}

\section{Adverse drug reactions and their preventability (Studies I, II and IV)}

Adverse drug reactions were defined according to the WHO (2) or a similar definition (48).

In the meta-analysis (Study I), studies which identified ADRs exclusively through spontaneous reporting or ICD codes were excluded, as these two methods underestimate the rate of ADRs (39, 196). To assess the preventability of ADRs, a case-by-case preventability assessment was required in the original studies. Thus, studies were excluded if they considered all dose dependent ADRs and those predictable from the pharmacological characteristics of the medication, as preventable without an explicit preventability assessment.

In study II, ADRs were detected in a stepwise manner in the elderly who had a healthcare encounter during the study period. Individuals' medical records data and dispensed medications from the SPDR were linked using their PIN. In the primary review, research pharmacists extracted information on suspected ADRs from the medical records for the 3-month study period, up to nine months before and three months after. In the secondary review, a clinical pharmacologist and a senior pharmacist independently assessed the causality between the prescribed medications and the suspected ADRs using the Howard criteria (197). Conflicting assessments were solved by consensus. Suspected ADRs with at least possible causality were considered. The seriousness of ADRs was assessed (48).

In study IV, persons were asked about their health conditions, medications and experienced ADRs in the past month using questions developed by the research group based on earlier studies (198, 
199). The definition of ADRs was not provided, as the survey targeted the general public. The questionnaire was tested with healthcare professionals, administrative personnel, the elderly, and immigrants to ensure the correct interpretation of questions.

\section{Sub-therapeutic effects (Studies III and IV)}

Three largely prescribed long-term medications (antihypertensive, lipid-lowering, and oral antidiabetic medications) were taken as examples. They were chosen as they require long periods of adequate adherent use to achieve the desired outcomes. In study III, elevated BP was detected from the medical records of individuals who had a healthcare visit in the period of three month in 2008. The reviewers of the medical records were not aware of participants refill adherence. Elevated BP was defined as a $\mathrm{BP} \geq 140 / 90 \mathrm{mmHg}$ or $\geq 130 / 80 \mathrm{mmHg}$ in individuals with diabetes mellitus (157). As the study aimed to investigate the association between non-adherence and elevated BP, the visit with the highest BP value was considered when multiple measurements were available. In study IV, questions on perceived STEs of antihypertensive, lipid-lowering, and oral antidiabetic medications one month prior answering the survey were developed, following a similar method as for ADRs.

\section{Assessment of inappropriate use of medications}

\section{Potentially inappropriate prescribing in the elderly (study II)}

The detection of PIPs was based on the Screening Tool of Older Person's potentially inappropriate Prescriptions (119). It consists of 65 criteria of overprescribing and misprescribing, including drugdrug and drug-disease interactions, unnecessary therapeutic duplications and medications which can increase the risks of cognitive decline and falls in older patients (119). Patients' medical histories, diagnoses, and current medications were recorded by one research pharmacist, other than those involved in the detection of ADRs. Prescribed medications were identified from the SPDR through their ATC codes during a six-month period in 2008 including three-months prior the period of review of medical records. Current diagnoses and medical histories were retrieved from the medical records and from patient administrative data through their ICD-codes. The research pharmacist referred to the research team in case of uncertainty regarding a criterion in individual cases. PIPs with at least possible causal contribution to the identified ADRs were considered. 


\section{Non-adherence to long-term medications (Studies III and IV)}

Two common measures of refill adherence were used: the 'proportion of days covered' method (PDC) (study III), and the 'cumulative measure of medication acquisition' (CMA) (study IV) (154). Both methods report medication availability by estimating the proportion of prescribed days' supply obtained during a specified observation period. The main difference between the PDC and the CMA is that PDC method truncates any oversupply, whereas adherence values of $>100 \%$ are allowed with the CMA, to include the oversupply (154). (Figure 3). In both studies, medications were identified through their ATC codes.

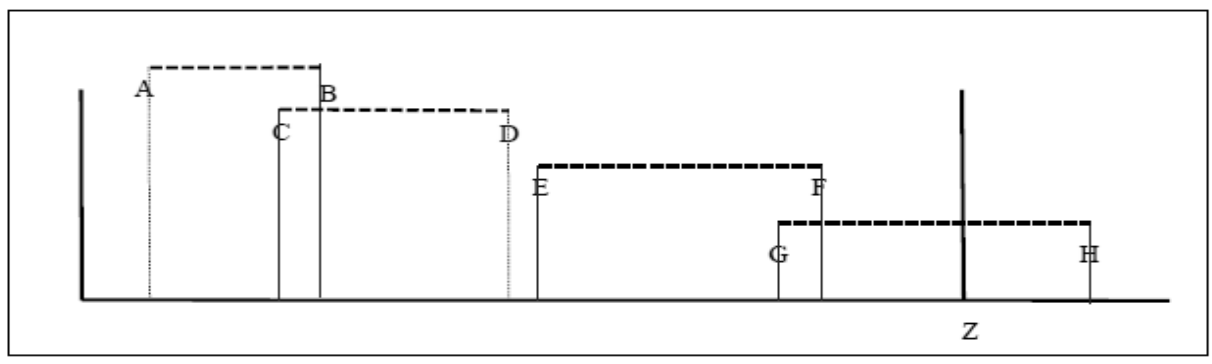

\begin{tabular}{|l|c|}
\hline Cumulative measure of medication acquisition (CMA) & Proportion of days covered (PDC) \\
\hline $\begin{array}{l}\text { Total refilled days of supply } \\
\text { Total days of follow up }\end{array}$ & $\frac{\text { Total of days the medication is available }}{\text { Total days of follow up }}$ \\
$=\frac{\text { Number days }(\mathrm{AB}+\mathrm{CD}+\mathrm{EF}+\mathrm{GZ})}{\text { Number of days between } \mathrm{A} \text { and } \mathrm{Z}}$ & $=\frac{\text { Number days }(\mathrm{AC}+\mathrm{CD}+\mathrm{EG}+\mathrm{GZ})}{\text { Number of days between } \mathrm{A} \text { and } \mathrm{Z}}$ \\
\hline
\end{tabular}

Z: End of the measurement period of adherence

Figure 3. Measure of refill adherence by the cumulative measure of medication acquisition and the proportion of days covered methods (154).

In study III, refill adherence was measured from the date of the first refill in 2007 (index date) until 01/01/2009 or until death, whichever occurred first. Two definitions of refill adherence to a multiple medication therapy were used: (i) adherence to at least one antihypertensive medication and (ii) adherence to the full antihypertensive therapy regimen, defined as adherence to all antihypertensive medications of the therapy regimen $(155,163)$. In order to compare to previous studies, patients with PDC $\geq 80 \%$ were considered as adherent (153-156). Moreover, to assess the sensitivity of measured adherence in predicting BP outcomes, the adherence 30 days prior to the BP measurement was also measured. 
In study IV, refill adherence was measured for a period of ten months preceding the completion of the survey. The same cut-off as for study III was applied to define undersupply. However, values $>100$ were not truncated, as the objective of the study was to investigate whether the oversupply, defined as a CMA $>120 \%$, was significantly associated with perceived DRMs (ADRs and STEs).

\section{Statistical analysis}

\section{Study I}

The summary measures for the percentage of patients with preventable ADRs and for the preventability of ADRs were calculated separately in different healthcare outpatient and inpatient settings. The meta-analyses was performed using DerSimonian and Laird random effects model with the estimate of heterogeneity being taken from the inverse variance random effect model (200). The percentage of patients with PADRs was calculated by dividing the reported number of healthcare visits with PADRs by the total number of healthcare visits. The preventability of ADRs was calculated by dividing the number of PADRs by the total number of ADRs.

\section{Study II}

The six-month prevalence of elderly patients with at least one PIPs was estimated, with the total number of the elderly who had a healthcare encounter during the study period as the denominator. The proportion of PIPs considered to have caused ADRs was calculated. The main organ systems and individual symptoms affected by ADRs were categorised according to the Medical Dictionary for Regulatory Activities (MedDRA) (201). The three-month prevalence of individuals with ADRs, and the proportion of ADRs considered caused by PIPs, were calculated. The association between PIPs and ADRs was investigated with a multiple logistic regression. The results were adjusted for age (65-74, 75-84, $\geq 85$ years), sex, number of dispensed prescribed medications three months prior the study period $(0,1,2-5,6-9, \geq 10)$, level of healthcare use (defined by Diagnosis-related group (DRG) weight (primary care exclusively (DRG weight=0), use of specialised inpatient or outpatient care (DRG weight>0)) (202), and use of multidose drug dispensing (203). A sensitivity analysis was performed without the 12 criteria excluded from the updated STOPP version (204).

\section{Study III}

The association between person's characteristics and non-adherence to any antihypertensive medication and to the full antihypertensive regimen was investigated with multiple logistic regressions. The results were adjusted for age $(<65,65-79, \geq 80$ years), sex, highest attained 
education (mandatory or less, secondary, post-secondary or higher), monthly individual disposable income (in quartiles, the $31^{\text {st }}$ December 2007; Q1=<Euro 99, Q2=Euro 100-139, Q3=Euro 140-

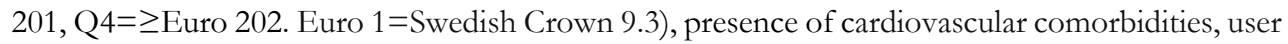
profile (new users (defined by no refill of antihypertensive medication one year prior to the index date), and prevalent user), number of antihypertensive medications in the therapy regimen (defined as the maximum number of dispensed antihypertensive medications during the study period), level of healthcare use, (primary care exclusively, use of specialised care). As the index date occurred in different dates in 2007, a Poisson regression analysis was performed to confirm that the measurement period of adherence did not affect the findings.

The association between non-adherence (long-term measures, and 30 days prior to the BP measurement) and elevated BP, was investigated using multiple logistic regressions, adjusted with the same covariates.

\section{Study IV}

The number and percentage of medications with oversupply, adequate supply and undersupply were reported for the three medication classes and at person-level. Chi-squared tests were used to analyse whether the percentages of perceived ADRs or STEs differed with refill behaviour.

In all studies, statistical significance was considered for $p<0.05$. In studies II and III, odds ratios (ORs) with 95\% confidence intervals (CIs) were calculated for each independent variable in the multiple regression models. The fit of the models was assessed using the Hosmer-Lemeshow test (205). Stata software versions 10 (Studies I and II), and 11 (Studies III and IV) was used for statistical analysis.

\section{Ethical considerations}

In study I exclusively aggregated, previously published data were used and therefore no ethical approval was required.

Studies II-IV presented ethical challenges due to the handling of sensitive personal data. The research studies were developed and undertaken in accordance with the Declaration of Helsinki (206). Informed consent of participants to studies II and III was not obtained. The retrospective study design did not affect the healthcare of included patients and it was believed that it was not possible to undertake the research with informed consent. Moreover, the studies were described 
in local media advertisements and potential participants could contact the study coordinators. The respondents to study IV explicitly consented to participating by answering the survey.

As the risk of intrusion to participants' personal integrity was considered for studies II-IV, data linkage was done by SCB and the registers datasets used in the studies were de-identified and analysed anonymously. Locating medical records in studies II and III required PINs, which were replaced with new identifiers after the review of medical records. SCB kept the code between the PINs and the new identifiers. Data were protected from being available to persons other than the researchers by confidential handling and storing. The researchers involved were committed to professional secrecy. The expected value of the research was considered to outweigh the integrity risks for the study subjects.

Ethical approvals were sought from the Regional Ethical Review Board in Gothenburg according to Swedish regulations on medical research on humans. Studies II and III are covered by the ethical approval no: 644-2008. Study IV is covered by the ethical approval no: 238-2010. 


\section{MAIN RESULTS}

\section{Preventable adverse drug reactions in healthcare settings (Study I)}

All included studies were conducted in hospital settings. Sixteen studies representing outpatients with 48797 emergency visits or hospital admissions and eight studies representing 24128 inpatients were included in the meta-analysis. The mean age of the study populations ranged between 38 (207) and 82 years (208), and studies included a majority of elderly patients. In total, PADRs occurred in 2.0\% (95\% CI 1.2-3.2\%) of outpatients and $52.0 \%$ (95\% CI: $42-62 \%$ ) of ADRs present at the time of hospitalisation or an emergency visit were considered preventable. Moreover, 1.6\% (95\% CI 0.1-51\%) of inpatients experienced a PADR during their hospital stay and $45.0 \%$ (95\% CI 33-58\%) of ADRs were considered preventable, but the percentage of hospitalised patients with PADRs could not be estimated precisely. The preventability was higher in the three studies including only the elderly (208-210), for which $71.0 \%$ (95\% CI $51-91 \%$ ) of ADRs were preventable.

All included studies in the meta-analysis used explicit criteria for determining the preventability, and the common criterion was that the PADR was due to an inappropriate medication treatment, taking into consideration the current knowledge of good medical practice. In studies that reported the causes of PADRs, the main reasons reported were inappropriate prescribing or inappropriate monitoring of commonly prescribed medications, such as: acetylsalicylic acid, digoxin, diuretics, nonsteroidal anti-inflammatory drugs (NSAIDs), and anticoagulants (Table 3).

Table 3. The main reported causes of preventable adverse drug reactions in included studies of the meta-analysis

\begin{tabular}{|c|c|}
\hline Study & Causes of PADRs \\
\hline $\begin{array}{l}\text { Alexopoulou } 2008 \\
\text { (Greece) (211) }\end{array}$ & $\begin{array}{l}\text { Prescription of too high doses of digoxin. Absence of protective } \\
\text { medications with NSAIDs or acetylsalicylic acid. Inappropriate } \\
\text { monitoring of anticoagulants }\end{array}$ \\
\hline $\begin{array}{l}\text { Baniasadi } 2008 \text { (Iran) } \\
\text { (212) }\end{array}$ & The reasons of PADRs not specified \\
\hline $\begin{array}{l}\text { Chan } 2001 \\
\text { (Australia) (208) }\end{array}$ & $\begin{array}{l}\text { Prescribing of multiple medications (cardiovascular, medications acting } \\
\text { on the central nervous system, anti-inflammatory, antithrombotic) }\end{array}$ \\
\hline $\begin{array}{l}\text { Courtman } 1995 \\
\text { (Canada) (210) }\end{array}$ & $\begin{array}{l}\text { Inappropriate dose or schedule of prescribed medications (antidiabetics, } \\
\text { digoxin, diuretics, antihypertensive, NSAIDs, warfarin, lithium) }\end{array}$ \\
\hline $\begin{array}{l}\text { Dartnell } 1999 \\
\text { (Australia) (213) }\end{array}$ & Inappropriate prescribing of corticosteroids, NSAIDs, antithrombotic \\
\hline
\end{tabular}


Table 3. The main reported causes of preventable adverse drug reactions in included studies of the meta-analysis (Continued)

\begin{tabular}{|c|c|}
\hline Study & Causes of PADRs \\
\hline $\begin{array}{l}\text { Davies } 2006 \\
\text { (United Kingdom) } \\
\text { (214) }\end{array}$ & The reasons of PADRs not specified \\
\hline $\begin{array}{l}\text { Davies } 2009 \\
\text { (United Kingdom) } \\
\text { (215) }\end{array}$ & Drug-drug interactions. Absence of prophylactic medications \\
\hline $\begin{array}{l}\text { Dormann } 2003 \\
\text { (Germany) (216) }\end{array}$ & $\begin{array}{l}\text { Inappropriate prescribing, in particular in the elderly with polypharmacy } \\
\text { (diuretics and analgesics) }\end{array}$ \\
\hline $\begin{array}{l}\text { Dormann } 2004 \\
\text { (Germany) (217) }\end{array}$ & Only medications causing ADRs were reported \\
\hline $\begin{array}{l}\text { Farcas } 2010 \\
\text { (Romania) (218) }\end{array}$ & $\begin{array}{l}\text { Drug interactions. High prescribed doses. (Main medications: } \\
\text { Acencoumarol, digoxin, theophylline, amiodarone) }\end{array}$ \\
\hline $\begin{array}{l}\text { Fransceschi } 2008 \\
\text { (Italy) (209) }\end{array}$ & $\begin{array}{l}\text { Inappropriate prescribing: Drug-drug interaction, drug-disease } \\
\text { interaction, medications not indicated, contraindication. No prescribing } \\
\text { of gastro-protective agents with acetylsalicylic acid or NSAID. } \\
\text { Insufficient monitoring (anticoagulants) }\end{array}$ \\
\hline $\begin{array}{l}\text { Gholami } 1999 \\
\text { (Iran) (219) }\end{array}$ & $\begin{array}{l}\text { Inappropriate dose interval. Inappropriate prescribed medication or dose, } \\
\text { Inappropriate monitoring. Inappropriate laboratory tests }\end{array}$ \\
\hline $\begin{array}{l}\text { Hopf } 2008 \\
\text { (United Kingdom) } \\
\text { (220) }\end{array}$ & $\begin{array}{l}\text { Inappropriate prescribing of NSAID and acetylsalicylic acid. Drug } \\
\text { interaction. The majority of medications responsible of ADRs were } \\
\text { prescribed in primary care }\end{array}$ \\
\hline $\begin{array}{l}\text { Olivier } 2002 \\
\text { (France) (221) }\end{array}$ & $\begin{array}{l}\text { Inadequate indication. Inappropriate monitoring. Previous history of } \\
\text { allergy. Self-medication }\end{array}$ \\
\hline $\begin{array}{l}\text { Patel } 2007 \\
\text { (India) }(222)\end{array}$ & Inappropriate prescribing \\
\hline $\begin{array}{l}\text { Pearson } 1994 \\
\text { (United States) (223) }\end{array}$ & $\begin{array}{l}\text { High doses or inappropriate dosing interval in patients with renal } \\
\text { dysfunction. Inappropriate monitoring of medications' serum } \\
\text { concentrations. Anticoagulant or thrombolytic prescribed despite } \\
\text { bleeding. Administration of antibiotics or narcotics despite known allergy }\end{array}$ \\
\hline $\begin{array}{l}\text { Pirmohamed } 2004 \\
\text { (United Kingdom) } \\
\text { (224) }\end{array}$ & $\begin{array}{l}\text { Inappropriate prescribing of NSAID and diuretics. High prescribed } \\
\text { doses of aspirin. Drug interactions }\end{array}$ \\
\hline $\begin{array}{l}\text { Pourseyed } 2009 \text { (Iran) } \\
(225)\end{array}$ & The reasons of PADRs not specified \\
\hline $\begin{array}{l}\text { Ruiz } 2008 \\
\text { (Spain) (226) }\end{array}$ & $\begin{array}{l}\text { Inappropriate monitoring (digoxin, acenocoumarol). Inappropriate } \\
\text { prescribing of antihypertensive and diuretics }\end{array}$ \\
\hline $\begin{array}{l}\text { Tafreshi } 1999 \text { (United } \\
\text { States) (227) }\end{array}$ & $\begin{array}{l}\text { Inappropriate prescribing or monitoring. Lack of patient education or } \\
\text { counselling }\end{array}$ \\
\hline $\begin{array}{l}\text { Van Der Hooft } 2008 \\
\text { (Netherlands) (207) }\end{array}$ & $\begin{array}{l}\text { Inappropriate prescribed medications: Too high doses, inappropriate } \\
\text { monitoring, absence of gastro protective therapy. Duplex anticoagulant } \\
\text { therapy }\end{array}$ \\
\hline $\begin{array}{l}\text { Zed } 2008 \\
\text { (Canada) (228) }\end{array}$ & The reasons of PADRs not specified \\
\hline
\end{tabular}

$\overline{A D R}$. Adverse drug reaction; NSAID: Non-steroidal anti-inflammatory drug; PADR. Preventable adverse drug reaction. 


\section{Potentially inappropriate prescribing and adverse drug reactions in the elderly (Study II)}

\section{Potentially inappropriate prescribing}

Data were collected from 813 elderly patients. Among them, $66.7 \%$ had exclusively primary care encounters. Overall, $46.0 \%$ received at least one PIPs during the period of six months. The prevalence of PIPs was $42.8 \%$ among those with exclusively primary healthcare contacts, $52.4 \%$ among those with specialised healthcare, and $66.1 \%$ among those hospitalised at least once during the 3-month study period. The most common PIPs were (i) inappropriate prescribing of acetylsalicylic acid (high dose or not indicated) (ii) medications that increase the probability of falls (long-acting benzodiazepines, antihypertensives in those with postural hypotension, long-term opiates) (iii) inappropriate prescribing of NSAIDs and corticosteroids, and (iv) prolonged use of medications acting on the central nervous system and psychotropic drugs.

\section{Potentially inappropriate prescribing and adverse drug reactions}

Overall, 19.6\% (159) of the study population experienced $\geq 1$ ADRs during the 3-three-month period, among them $40.9 \%$ (65/159) had $\geq 1$ ADR considered caused by PIPs (Figure 4). At ADR level, 245 ADRs were identified, among them 73 were considered as caused by PIPs $(29.8 \%$ of all ADRs).

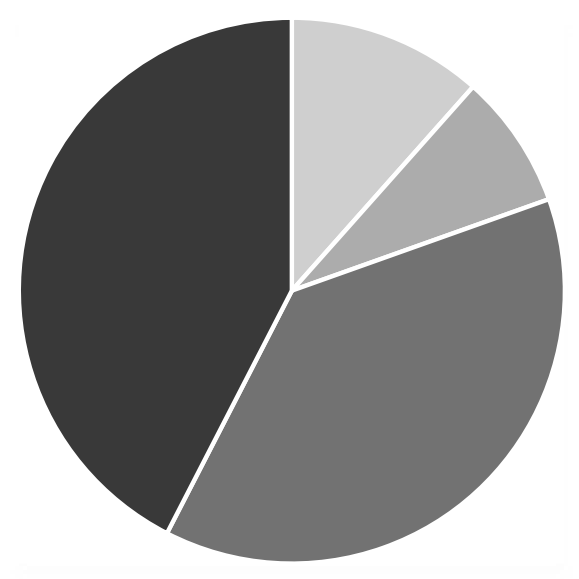

Persons with ADRs not caused by PIPs (94/813) $11.6 \%$

- Persons with $\geq 1$ ADRs caused by PIPs (65/813) $8.0 \%$

- Persons with $\geq 1 \mathrm{PIPs}$ but no ADRs (309/813) 38.0\%

- Persons with no PIPs and no ADRs (345/813) $42.4 \%$

ADRs: Adverse drug reactions; PIPs: Potentially inappropriate prescriptions

Figure 4. The association between PIPs and ADRs among the study population 
The multiple regression analysis found that persons prescribed PIPs had increased odds to experience ADRs (OR 2.47, 95\% CI 1.65-3.69). When the sensitivity analyses were limited to the 53 criteria included in the updated STOPP version (204), PIPs remained significantly associated with the occurrence of ADRs (OR 2.57, 95\% CI 1.75-3.77).

PIPs were considered the cause of a high percentage of ADRs affecting the vascular and nervous systems (60.0\% and 50.0\% respectively). Moreover, $62.5 \%$ of ADRs resulting in falls were considered to be caused by the inappropriate use of benzodiazepines. Twelve serious ADRs were identified; among them eight were considered to be caused by PIPs, mainly by antipsychotics and NSAIDs. One death was considered to be caused by the long-term use of nitrazepam.

\section{Non-adherence to long-term medications and related morbidities (Studies III and IV)}

\section{Non-adherence to long-term medications}

In study III, $34.9 \%$ of the study population was non-adherent to the full antihypertensive regimen, and $12.7 \%$ was non-adherent to any antihypertensive medication (complete non-adherence). Among survey respondents (study IV), 21.9\% of the long-term medications were oversupplied and $12.4 \%$ were undersupplied.

\section{Factors associated with non-adherence}

In study III, the multiple logistic regression found that non-adherence to any antihypertensive medication was more common among persons younger than 65 years old (OR 2.75, 95\% CI 1.186.43) and those with the lowest income (OR 2.05, 95\% CI 1.01-4.16) (Figure 5). Non-adherence to the full antihypertensive regimen was more common among new users (OR 2.04, 95\% CI, 1.323.15 ) and those who used more healthcare resources (OR 1.63, 95\% CI, 1.14-2.32) (Figure 6).

Persons with multiple antihypertensive medications were more likely to be adherent to any medication (OR 0.46, 95\% CI $0.28-0.75$ and OR $0.24,95 \%$ CI $0.13-0.45$ for 2 and $\geq 3$ antihypertensive medications respectively) and less likely to be adherent to the full therapy (OR 1.85, 95\% CI 1.25-2.75) and OR 5.22, 95\% CI 3.48-7.83 for 2 and $\geq 3$ antihypertensive medications respectively) (Figures 5 and 6). Gender, level of education and presence of cardiovascular comorbidities did not affect adherence. 


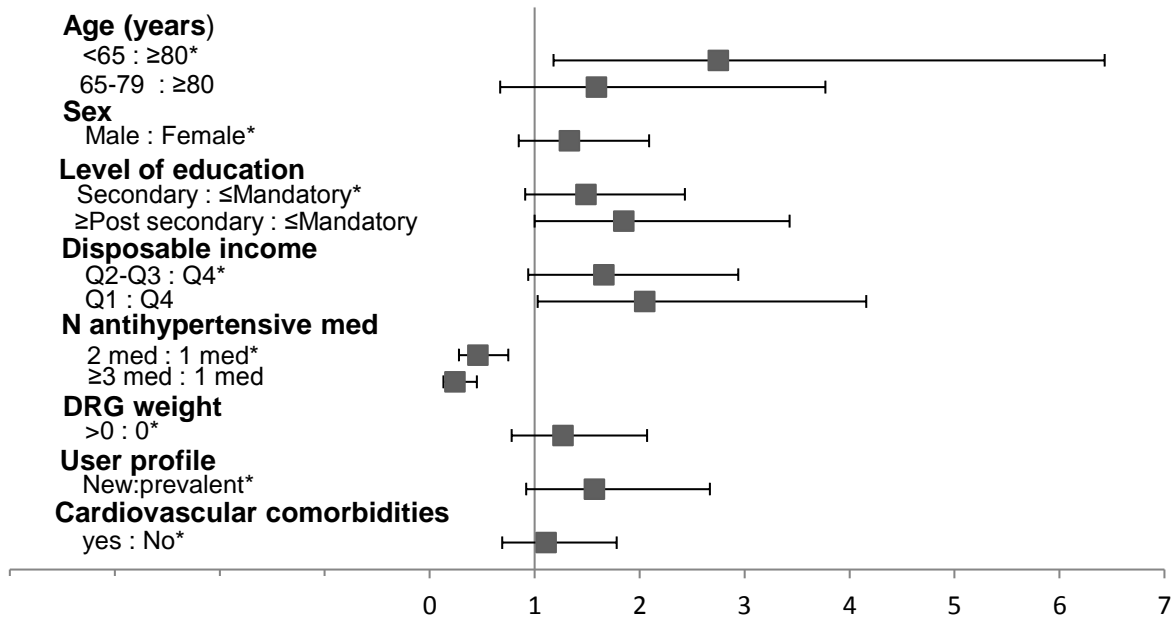

*Reference group in the regression analysis. DRG Weight: Diagnosis Related Group weight; New: New user of antihypertensive therapy; Q: Quartile of income.

The multiple regression model was adjusted for number of hypertension medications in treatment regimen, sex, age, highest attained education, disposable income, DRG weight and presence of cardiovascular comorbidities.

Figure 5: Factors associated with non-adherence to any antihypertensive medication

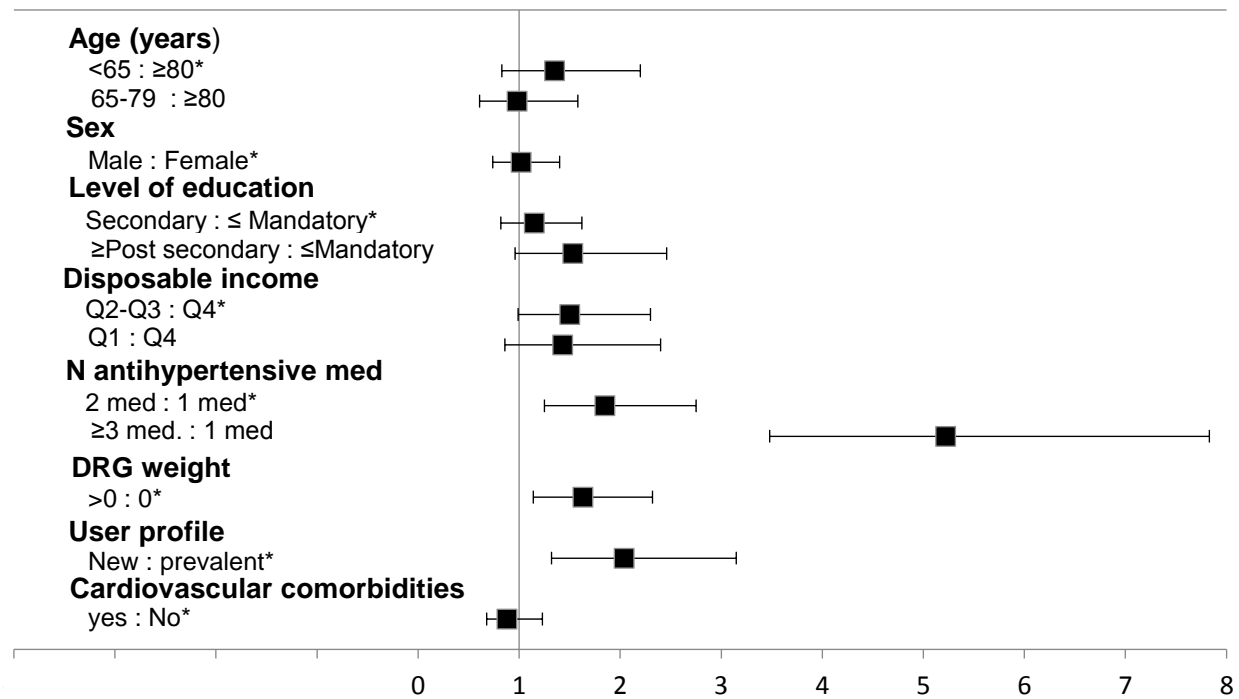

*Reference group in the regression analysis. DRG Weight: Diagnosis Related Group weight; New: New user of antihypertensive therapy; Q: Quartile of income.

The multiple regression model was adjusted for number of hypertension medications in treatment regimen, sex, age, highest attained education, disposable income, DRG weight and presence of cardiovascular comorbidities.

Figure 6. Factors associated with non-adherence to the full antihypertensive therapy 


\section{Non-adherence and drug-related morbidities}

In study III, the proportion of individuals with elevated BP was significantly higher among those who were non-adherent to any antihypertensive medication 30 days before the measurement of BP (Figure 7). The association remained significant when the analysis was adjusted with covariates (OR 3.27, 95\% CI 1.27- 8.49). The long-term measures of adherence were not associated with elevated BP.

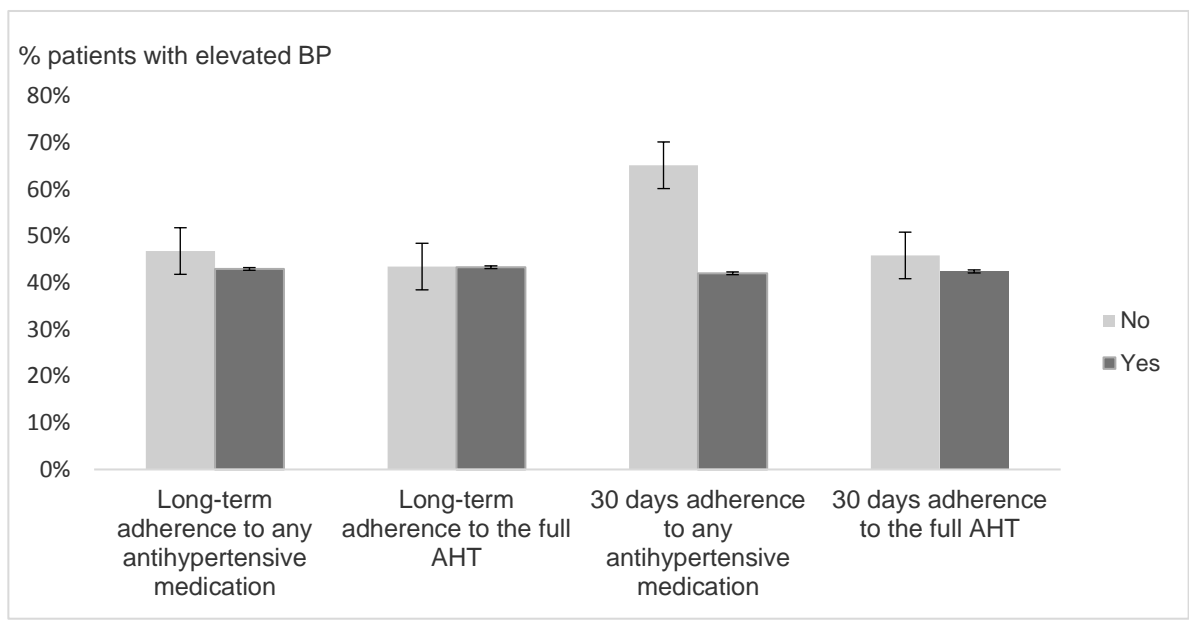

AHT: Antihypertensive therapy; BP: Blood pressure

Figure 7. Association between different measures of refill adherence and elevated blood pressure from medical records

In study IV, the percentages of self-reported ADRs and STEs did not differ between medications with adequate refill adherence, oversupply, and undersupply for the three therapeutic classes. These percentages were respectively $2.6 \%, 2.7 \%$, and $2.1 \%(\mathrm{p}>0.5)$ for ADRs and $1.1 \%, 1.6 \%$, and $1.5 \%(\mathrm{p}>0.5)$ for STEs (Figure 8). For lipid lowering medications and oral anti-diabetics, differences in reporting ADRs or STEs for medications with different refill behaviour could not be statistically analysed because of few reported ADRs and STEs. 


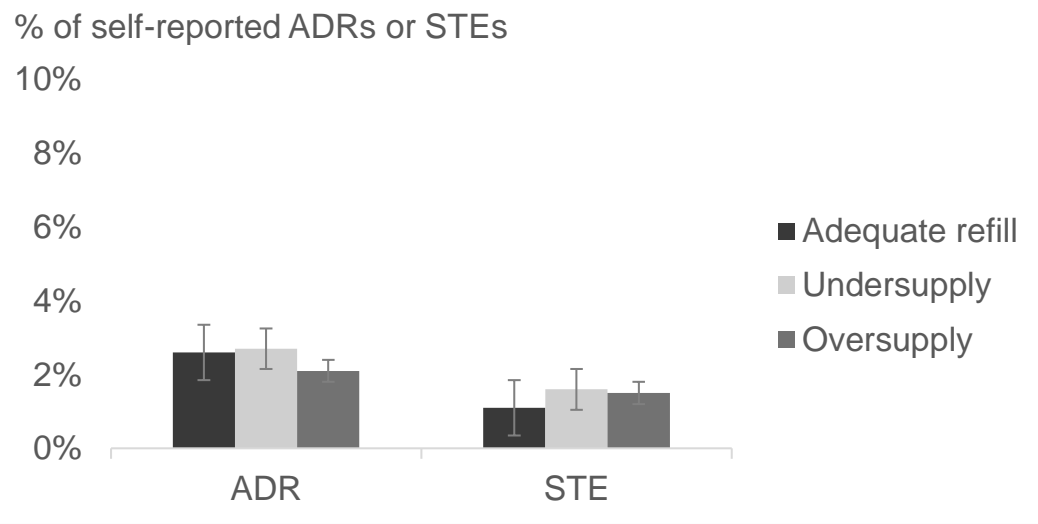

ADR: adverse drug reaction; STE: Sub-therapeutic effect

Adequate refill: Cumulative measure of medication acquisition (CMA) $\geq 0.8$ and $\leq 1.2$; Undersupply: CMA $<0.8 ;$ Oversupply: CMA $>1.2$

Figure 8. Association between refill behaviour and perceived adverse drug reactions and sub-therapeutic effects 


\section{DISCUSSION}

\section{Preventable adverse drug reactions in healthcare settings}

The finding of this thesis that $2 \%$ of outpatients being hospitalised or visiting emergency department experience PADRs was lower than in a previous review on all DRMs, where at median, $4.3 \%$ of all admissions among outpatients were due to PDRMs (93). Their higher estimate compared to the percentage of patients with PADRs in study I was expected, as they included other DRMs such as STEs and drug intoxications in their analysis. The percentage of inpatients who experienced a PADR could not be estimated precisely as only two studies were identified. Another review found that at median, 1.8\% of inpatients experienced a PDRM (36). However, predictable ADRs due to the characteristics of the medication were excluded from their analysis.

The approximately $50 \%$ preventability of ADRs among adult outpatients was higher than in earlier reviews, in which the median and pooled preventability of ADRs among patients being hospitalised has been $31 \%$ and $29 \%$, respectively $(47,54)$. The difference may arise from inconsistent definitions for ADRs in previous reviews. For providing consistent estimates, the WHO's (2) or a similar (48) definition for ADRs was required in study I, while previous reviews on outpatients have accepted various definitions for $\operatorname{ADRs}(47,54)$. The criteria for preventability may also have influenced differing preventability estimates. An original preventability assessment in included studies was required in this meta-analysis while previous reviews have used more narrow criteria, such as exclusively considering ADRs due to inappropriate medication selection or dose as preventable. Therefore, PADRs caused by other reasons may have been overlooked in previous studies resulting in lower preventability estimates. Moreover, although the time period of the bibliographic research was not limited in this meta-analysis, the majority of included studies were published in the 2000's, while previous reviews have included older studies. The growing interest in medication safety since the 1990's (87) may have reinforced the acknowledgement of ADR preventability in newer studies. Two previous reviews among inpatients have found a median preventability of all DRMs of $35 \%$ and $46 \%$ respectively $(36,37)$, which were comparable to study I estimates on preventability of ADRs among inpatients.

The preventability of ADRs was higher in studies including exclusively elderly patients. Although the few number of studies including exclusively elderly patients would hinder drawing any conclusion regarding the increase of preventability of ADRs with age, this is in accordance with 
previous evidence about the challenge to ensure appropriate and safe use of medications among the elderly population $(94,101)$.

\section{Implications}

IUM was the cause of about half of ADRs among inpatients and outpatients. PADRs should be considered as a failure of the therapy care system $(76,77)$. Yet, there is also a need to identify and study the stage of the medication use process where most unsafe acts are committed in order to target interventions. According to the findings of the meta-analysis, IUM causing PADRs appears to occur commonly at the prescribing and monitoring stages. Therefore targeting interventions to improve the appropriate use of medications to prescribing and monitoring stages could have a potential benefit in preventing ADRs.

Knowledge on the percentage of patients with PADRs and the preventability of ADRs in primary care or in the general population is limited, since no studies were identified among outpatients without a hospital admission or emergency visit. This supports the need to extend the research on ADRs due to IUM to the general population and all healthcare settings, including primary care. A recent study conducted in the general Swedish adult population found that the majority of ADRs were not serious and different in nature than those occurring in hospital settings (21). Since serious ADRs have been found more preventable than others (21), the preventability of ADRs occurring in the general population may be different than found in this thesis. Furthermore, medications responsible for ADRs causing emergency visits or hospitalisations are mainly prescribed in primary care (207). Thus, interventions to prevent ADRs, implemented exclusively in hospital settings to target serious ADRs, would omit an important proportion of ADRs, which may be less serious but cause discomfort and worsen perceived quality of life of patients $(29,30)$.

\section{Potentially inappropriate prescribing and adverse drug reactions in the elderly}

\section{Potentially inappropriate prescribing}

The nearly 50\% prevalence of PIPs among the elderly across care settings found in this thesis was higher than previous studies in primary care using other criteria (101). However, there is a large variation in the prevalence of PIPs between studies, depending on the study setting and design and the PIPs criteria used $(101,229,230)$. Notwithstanding, STOPP criteria have been found more sensitive than others in detecting PIPs in European healthcare settings (231-233). The prevalence 
of PIPs in studies based on STOPP criteria have ranged between 21\% and 79\% (233). However, the comparison between studies should be done with caution because of different settings and populations. In accordance with previous findings $(94,234)$, the prevalence of PIPs was higher in specialised care compared to primary care. Persons using more advanced care probably have more complex co-morbidities, which has been associated with PIPs (235). However, the elderly in specialised care may not be representative of the elderly population as a whole. Despite an absence of an exact estimation of the prevalence of PIPs, it is evident from the thesis findings and from numerous others $(101,229,230)$, that PIPs are common in the elderly. Thus, preventive measures adapted to different settings are needed.

The use of long-acting benzodiazepines and neuroleptics as long-term hypnotics were among the most common PIPs in this thesis, similar to studies using STOPP criteria conducted in nursing homes and hospital settings $(105,124,231,236)$. Acetylsalicylic acid was the most common PIPs, mainly for primary prevention of cardiovascular complications, as in other studies, conducted exclusively in primary care settings and among community dwelling elderly (95, 237). However, acetylsalicylic acid was less commonly reported in studies on PIPs conducted in specialised care settings, which may be explained by the different prescribing patterns between primary and specialised care. The variation in the most common PIPs between studies may also be explained by differing local clinical prescription guidelines, prescribing regulation, population and disease burden $(121,238,239)$. The availability of some medications included in the PIPs criteria as OTC medications, such as acetylsalicylic acid and some NSAIDs, may cause an underestimation of their inappropriate use in studies using exclusively prescription data.

\section{Potentially inappropriate prescribing and adverse drug reactions}

The elderly using PIPs had more than two-fold increased odds of experiencing ADRs, suggesting that PIPs cause potentially preventable morbidity across care settings. These findings are in accordance with the few studies, mainly conducted in hospital settings, which have investigated the association between the PIPs STOPP criteria and ADRs $(95,117,231)$. Since STOPP criteria are currently largely used to evaluate the quality of prescribing in the elderly, this finding extends the evidence on their predictive value to detect ADRs across healthcare settings, including primary care. The main limitations of other prescribing criteria, including the widely used Beers, is the lack of evidence on causal association with adverse health outcomes including ADRs (109, 110, 240). Moreover, while previous studies have found that PIPs, defined by other criteria, were the cause of a relatively small percentage of ADRs $(241,242)$, one third of detected ADRs in this thesis was 
considered to be caused by PIPs, which suggests that interventions aiming at improving the prescribing of medications also leads to prevent certain ADRs in the elderly. But the evidence is still scarce.

Similar to a recent study on PIPs conducted in community dwelling elderly (95), most ADRs considered to be caused by PIPs were non-serious, while previous studies have mainly focused on the associations between PIPs and serious adverse outcomes, such as hospitalisation and death $(98,99)$, or were conducted among hospitalised patients $(117,132,133)$, who may experience more serious ADRs, compared to the general population $(198,243)$. However, even non-serious ADRs are important to consider as they are associated with lower quality of life and may cause prescribing cascades to treat symptoms of unrecognised ADRs $(29,30,198)$, especially if safer therapies exist.

Based on the findings of this thesis, the PIPs listed in the STOPP criteria are particularly sensitive in detecting ADRs affecting nervous and vascular disorders and ADRs resulting in falls. This finding complements previous evidence as ADRs caused by PIPs have not been previously categorised by system organ classes and symptoms. Falls have been the most common adverse outcomes identified by STOPP criteria in a study conducted in a hospital setting (117). Moreover, interventional studies to improve the quality of prescribing in nursing homes have found a significant decrease in the number of falls among the intervention groups $(244,245)$, but not in other health outcomes (245). However, these interventional studies should be interpreted with caution because of small samples, and the characteristics of study populations. Similar to previous research on DRMs $(82,84)$, the most common ADRs were those affecting the gastro-intestinal and cardiovascular systems. However, only a few of them were considered to be caused by PIPs in this thesis.

\section{Implications}

In this thesis, PIPs were common across healthcare settings. Prescribing patterns and traditions and patients' characteristics differ between hospitals, nursing homes, and primary healthcare (246, 247). Therefore, knowledge of the most common PIPs in each setting, especially those associated with adverse outcomes, is advocated in order to tailor interventions to improve prescribing to healthcare structure needs. Since a large proportion of elderly people use mostly primary care, interventions to improve prescribing of the elderly should also be implemented in primary care.

The findings of this research suggest that decreasing PIPs could contribute towards ADR prevention, in particular falls and associated symptoms. Elderly patients may be unable to 
recognise the symptoms of conditions that increase the risk of falls, such as hypotension or dizziness; or they may not report them to their healthcare givers, increasing the risk of experiencing falls, if the medication regimen is not adjusted (248). Safety issues of medications with repeat prescribing, including antihypertensive medications, have also been warranted (249). Although falls are considered multifactorial by nature (250), medication review may help to reduce the risk of fall among elderly patients (251).

Reducing both inappropriate prescribing and ADRs requires system interventions to routinely evaluate medication appropriateness, effectiveness and to monitor safety, while balancing the risk of underuse of beneficial medications (252). The PIPs criteria aim to evaluate and improve the quality of prescribing in the elderly. Yet, they also imply the improvement of other stages of the medication use process, such as the monitoring of renal functions when medications with narrow therapeutic intervals are prescribed, or control coagulation with medications increasing the risk of bleeding such as acetylsalicylic acid. Even when medications are appropriately prescribed, they may be associated with ADRs, such as gastrointestinal bleeding with acetylsalicylic acid (224). Improving the quality of prescribing requires a collaboration of prescribers and other healthcare professionals and a better continuity of care for elderly patients with chronic conditions (253). Moreover, patients should be engaged in monitoring their medications to track their perceived adverse outcomes (252). Prescribers' views about PIPs should also be considered in order to improve the understanding of the reasons of inappropriate prescribing in the elderly despite the availability of safer and evidence-based alternatives (254).

Several interventions have been suggested to improve the quality of prescribing in the elderly (255). Yet, the applicability of the prescribing criteria in clinical practice and community pharmacy needs to be established. In Sweden, developed and implemented interventions include: the development of national quality prescribing indicators (256); the education of healthcare professionals to geriatric pharmacology and the creation of regional recommendations for drug therapy in the elderly by the Drug and Therapeutic Committees; computerised decision support systems (257); medication review in primary care and nursing homes $(258,259)$; medication reconciliation at hospital discharge (260) and pharmacist-based interventions (261). Moreover, the Swedish government has provided financial incentives that award counties achieving performance targets for certain local prescribing indicators (262). The Swedish National Board of Health and Welfare annually publishes healthcare quality indicators including several indicators of drug utilisation among the elderly in order to direct attention to areas of possible improvement (263). These efforts have shown a positive effect on the quality of prescribing in the elderly according to local indicators 
(264). Future research should focus on studying whether improving the quality of prescribing is translated into improved health outcomes of the elderly.

\section{Non-adherence to long-term medications and related morbidities}

\section{Non-adherence to long-term medications}

The finding of this thesis that persons taking a multidrug therapy are more adherent to at least one medication in their therapy than to the full therapy regimen demonstrates that adherence rates vary by the definition for non-adherence. In previous studies, adherence rates varied widely from $35 \%$ to $97 \%$ for antihypertensives $(265,266)$; from $37 \%$ to $80 \%$ for lipid-lowering medications (267); and from $36 \%$ to $93 \%$ for oral anti-diabetics (268), depending mainly on population characteristics and measurement methods. Yet, only a few studies have considered the multidrug-therapy when adherence was measured from refill data and have distinguished between the two definitions of non-adherence $(155,163)$. The results of this thesis support considering the use of multiple medications when measuring adherence.

The findings of this research corroborate the conclusions of previous studies on the commonness of oversupply of largely prescribed long-term medications (152, 170, 174, 175). The high percentage of oversupply may be explained by the Swedish reimbursement system (269). Longterm medications are often prescribed for three months and can be refilled when two-thirds of the previous medication period has passed. Moreover, the reimbursement increases during a calendar year with the accumulated co-payment (269), which may provide incentives to stockpile and oversupplies, especially for individuals exempted from co-payment.

\section{Factors associated with non-adherence}

The results of this thesis add to previous evidence that persons younger than 65 years and those with the lowest incomes are more often non-adherent to any medication in their therapy. Although younger age and lower socio-economic status have been previously identified as barriers to adherence to long-term medications $(164,166,270)$, previous research has not considered the two distinct measures of non-adherence to a multidrug therapy. Working-age persons' non-adherence to any medication may be explained by the difficulty they face to include a regular medication intake routine in their daily schedules or by their perception of treatments for often asymptomatic conditions as unnecessary (270). The commonness of non-adherence to any medication in persons with the lowest income may be explained by multiple factors, including financial barriers (271). 
Although the Swedish Pharmaceutical Benefits Scheme has universal coverage independently of an individual's income (269), the effect of socio-economic status on non-adherence found in this thesis suggests a healthcare inequality. In addition, health behaviour of persons with lower socioeconomic status has been suggested to partly explain non-adherence (272).

This thesis confirms previous findings on the commonness of non-adherence among persons using specialised healthcare and new users $(167,273)$. It also supplements the previous evidence that these two groups are adherent to at least one medication but not the full therapy regimen. Persons using specialised healthcare may have more comorbidities, and may prioritise managing symptomatic conditions over controlling an asymptomatic condition such as hypertension (165). Among new users, the lower adherence to the full therapy regimen may be due to a switch to another antihypertensive class to adjust the treatment. Moreover, previous research has found that more than one out of five patients discontinues their initial medications during the first year (274), partially because of concerns of dependence and ADRs of multiple medications (275).

Consistent with a previous large study [163], individuals were more likely to adhere to at least one antihypertensive medication and less likely to adhere to their full therapy. Higher rates of nonadherence to the full therapy regimen among persons with multiple antihypertensive medications may reflect the difficulties that patients face in following more complex treatment regimens. The better adherence to at least one medication with additional medications may be due to people taking multiple medications having more occasions to refill any medication in their therapy. While some studies have found a better adherence for additional concurrent medications (276), this study highlights the variability in the effect of the number of medication on the overall adherence when applying two different definitions of adherence to a multidrug therapy.

\section{Non-adherence and drug-related morbidities}

The findings of this thesis that long-term measures of non-adherence were not associated with higher percentages of clinical and perceived STEs of long-term therapies confirm the evidence from systematic reviews and meta-analysis on the complexity of studying the association between adherence and health outcomes in real-life settings (277-279). Some previous studies that have found an association between refill adherence and health outcomes have either included patients from insurance databases $(136,139,163)$; new users $(280,281)$; those using a monotherapy $(140)$; measured the adherence to one therapeutic class in persons with a multidrug therapy (282); or were conducted in controlled clinical trials (71), which may not represent patients from the general population. The absence of an association between long-term measures of adherence and STEs to 
the prescribed long-term medications may be explained by the effects of important factors other than adherence in the management of chronic cardiovascular diseases, diabetes, and hyperlipidaemia. As recognised by the WHO, the adherence to healthy behaviour, such as cessation of smoking, a balanced diet and regular physical activity also has a great impact on the management of cardiovascular chronic conditions (62). Long-term measures of adherence may be a marker of individuals' overall healthy behaviour (58), known as the "healthy adherer effect" (283), as a better adherence to placebo has been associated with better outcomes in controlled clinical trials (284). Nonetheless, the low number of perceived STEs in the survey study may also be due to asymptomatic conditions, as persons may have failed to identify disease symptoms associated with STEs $(65,66,285)$.

Non-adherence to any antihypertensive medication a month prior to a healthcare visit was associated with elevated BP, while no significant difference was found for non-adherence to the full therapy regimen. The difference between the findings of the short and long-term measures of non-adherence to any medication on health outcomes may be explained by the phenomenon of "white-coat adherence", as patients commonly improve their medication-taking behaviour in the short period before and after their appointment with their healthcare provider (147). The impact of non-adherence to the full therapy regimen on clinical outcomes may also depend on the characteristics of prescribed medications, such as their duration of action. Some research highlights the importance to consider the "forgiveness" of prescribed medications when studying the association between non-adherence and health outcomes, and to adjust the threshold to define non-adherence to the medication characteristics (286), but this was beyond the scope of this research.

In this thesis, the oversupply of prescribed long-term medications was not associated with increased perceived DRMs. Although previous research has found oversupply associated with adverse health outcomes, such as hospitalisation $(174,177,178)$, study IV of this thesis is the first to investigate an association between oversupply, as a form of refill non-adherence, and perceived DRMs. The absence of an association between refill behaviour and perceived DRMs may be in part due to the low number of perceived ADRs and STEs. The low number of reported ADRs may have been contributed by respondents' insecurity of a medication's causality with the experienced symptoms. Previous research has found that patients may experience an ADR for a long time before informing their healthcare provider (248).

\section{Implications}


The finding of this thesis that factors associated with non-adherence to a multidrug therapy differ for the two definitions of non-adherence improves the understanding of barriers to adherence in clinical practice. Furthermore, this information can be used to tailor interventions to improve adherence to patients' needs. For example, it is important to understand whether a patient is nonadherent to any prescribed medication, or whether he has hinders to adhere to a complex multiple drug therapy, requiring decreasing the complexity of the regimen. Moreover, the extent of disparate interpretations of the effect of multiple medications on adherence may pose decisionmaking issues for health practitioners for the management of chronic diseases that require a multidrug therapy. A healthcare provider has to consider whether a patient must adhere to all medications as prescribed, or whether the adherence to at least one medication in the therapy regimen may be considered as acceptable (156).

Numerous multi-level interventions to promote adherence have been developed (277, 287). Given the complexity of implementing interventions in clinical practice, some authors suggest selecting the most effective component considering the patient's individual situation (277). For instance, working-age persons and those with the lowest socio-economic status, being those most commonly non-adherent to any medication, may benefit from education about their chronic condition and the importance of taking their medications. Moreover, the physician should discuss with the patients the best time of the medication intake in order to reduce forgetfulness (74). Emerging technologies, such phone reminders, have been promoted to improve adherence, but evidence on their efficacy in real-world settings is limited (288). The healthcare giver should also recognise patients' economic constraints as a potential barrier to adhere to any medication and may choose to prescribe less costly medications (74). Persons with multiple medications, those with co-morbidities and new users would benefit from a reduction of the prescribing complexity, such as the use of fixed combinations, and once-daily dosing $(289,290)$, and have appropriate information when any new prescribed medication is introduced in the therapy.

Monitoring the refills of any prescribed medication prior to healthcare visits may facilitate interpreting the STE of prescribed medications prior to adjusting the therapy regimen (291). The clinician may attribute uncontrolled conditions to therapeutic ineffectiveness and increase the dosage of current medications which can potentially lead to ADRs. Assessment of adherence in the clinical routine could be feasible, as the measure of refill-adherence to any antihypertensive medication is a non-invasive, sensitive and easy to calculate method. Yet, there is a lack of evidence on how to introduce it into clinical practice. Moreover, the effect of white-coat adherence should be considered, when considering the effect of adherence on health outcomes as previously 
discussed (147). The two-way communication between physicians, pharmacists and patients should be enhanced to improve the rational use and adherence of long-term, repeat prescribing medications (179).

Oversupply was common, and even if it may not lead to higher occurrence of ADRs, it remains a source of extra high costs and wastage of healthcare resources $(142,174,176,177)$. Although this thesis did not focus on generic substitution, it should be highlighted that with generic substitution, patients may stockpile the same medication in different packages, appearances and names. Previous research has found that up to ten percent of patients in certain social groups erroneously used two equivalent medications or were unaware of their equivalence (168). The risk of overuse of the same medication may increase with the oversupply, especially in the elderly who have cognitive and sight decline. Healthcare providers should approach and inform each patient individually; especially the elderly and those with multiple long-term medications, and better monitor their refilled medication.

The thesis findings that STEs were present in more than $40 \%$ of patients adherent to the full therapy regimen, and that only a few survey respondents perceived DRMs from their long-term regimen, confirms the importance of considering the whole picture of the medication use process to improve both medication use and outcomes. Numerous interventions that showed an improvement of adherence were not followed by improvements of associated health outcomes (277). Therefore, it is of importance to consider if patients were prescribed appropriate medications at the appropriate doses and dose-intervals, and whether they are well monitored and informed about their medications and conditions (144).

\section{Methodological considerations}

\section{Meta-analysis on preventable adverse drug reactions}

Study I was the first meta-analysis to estimate the percentage of patients with PADRs using explicit criteria of preventability and standardised definitions of ADRs. Seven bibliographic databases and a wide range on common search terms on DRM and preventability were used to increase the likelihood to capture relevant articles. Search strategy was comprehensive, but arduous with a large number of citations. However, research was limited to studies published in English. Therefore, some relevant studies published in other languages may have been omitted. 
Compared to previous reviews $(36,47,54,93)$, the meta-analysis provides more consistent estimates on the preventability of ADRs and the proportion of patients with PADRs. The outcome measure was more standardised as WHO's (2), or a similar definition (48), for ADRs was required to decrease the heterogeneity between studies. Nonetheless, the diverse definitions and various methods for assessing the preventability contributed most likely to the heterogeneity, and should be considered while interpreting the results. The existing instruments should be improved and standardised to assess the preventability more accurately and to better identify common contributing factors of PADRs that interventions should target in priority.

This thesis focused on estimating the preventability ADRs, since they are a common category of DRMs and the most consistently defined. However, there is a need for more standardised definitions of the other categories of DRMs to enhance the knowledge of contributing factors and facilitate the comparison across studies.

\section{Information on inappropriate use of medications}

One strength of this thesis is the use of multiple and complementing data sources to study two common aspects of IUMs: the PIPs in the elderly and non-adherence to commonly prescribed long-term medications. However, some weaknesses of this research should be acknowledged. Other drug-related problems common in the elderly would have been relevant to consider, as they may have also contributed to the occurrence of DRMs $(18,292)$. Moreover, the results of studies are not possible to combine, such as the association between inappropriate prescribing and nonadherence, which would have given a better picture of the IUMs as a whole. In addition, as previously discussed, the monitoring of medications would have been important to consider as some medications listed in PIPs may be appropriate with an appropriate monitoring (252). Yet, the nature of register data, did not allow an exploration of other possible aspects of IUM. The results of studies III and IV were not possible to combine, such as comparing the proportions of persons who reported STEs and those with STEs from their medical records. However, this was not feasible, as this would have required informed consents of participants of the medical record study and would have therefore decreased its representativeness.

Sampling errors were not a concern in studies II-IV as study populations were identified from a random sample of the Swedish adult population, drawn by SCB. However, selection bias among persons who visited a healthcare setting during the three-month period should be considered in study III, because of the difference of their characteristics with the total study population. A response bias is also considered in the survey study because of the answer rate of around $50 \%$ and 
the over representation of persons with high socio-economic status, those with a Swedish background, and the elderly (195); but the high rate of the elderly was expected because of the studied medications. Persons with severe medical conditions might not have answered the survey. However, some of them may require multidose dispensing and would therefore be excluded from the analysis.

\section{Potentially inappropriate prescribing in the elderly}

Study II is the first to investigate the association between PIPs according to STOPP criteria and ADRs among a representative sample of the elderly general population. Nevertheless, the findings should be interpreted with some limitations in mind. The SPDR has full coverage of dispensed prescribed medications in Swedish pharmacies and nursing homes but does not include prescriptions during hospitalisations and emergency medications in nursing homes and specialised care (192). However, a small proportion of the elderly had short hospitalisation episodes during the study periods, which may not affect findings. The results could not be stratified by the type of residence due to unavailability of these data. Although previous studies have found significant differences in PIPs by type of residence (234), the potentially small number of elderly living in nursing homes (293), with regards to the total sample size, would limit interpreting such stratified analysis. The inappropriate use of some medications listed in the PIPs and available as OTC medications, such as acetylsalicylic acid and some NSAIDs, may not be estimated accurately.

One strength of study II was the record-linkage of pharmacy claims data with clinical information from inpatient and primary care medical records, in order to gain more insight on the patient's specific inappropriate medications. Nevertheless, some PIPs criteria were impossible to evaluate in cases with insufficient clinical information and history (e.g. information about an intact uterus).

Some limitations are associated with the use of explicit criteria of PIPs, as they do not incorporate patient's preferences and individuality. Moreover, some medications classified as PIPs may be appropriate for patient circumstance. Therefore, the dichotomisation of prescribed medications into appropriate versus inappropriate may be an oversimplifications of the clinical situation in real life practice.

STOPP criteria were selected to evaluate the quality of prescribing, as these criteria have been endorsed by different jurisdictions and research groups in Europe and elsewhere to evaluate the quality of prescribing in the elderly (120-126), and in order to facilitate the comparison with other studies. However, there are nationally developed criteria that have been adapted to Swedish 
settings (111). The structure of nationally developed criteria is similar to STOPP. Furthermore, some criteria overlap, but other STOPP criteria are not considered as inappropriate in Sweden (Appendix 1). There is therefore a need for standardised criteria to compare findings between studies. The association of national criteria with ADRs will be investigated in future research.

Similar to previous research, this study focused on overprescribing and misprescribing. However, underprescribing of indicated medications has also been reported as an important cause of DRMs, such as therapeutic failures (294). Therefore, future research should also consider the underprescribing of evidence-based indicated medications to reduce PIPs in the elderly.

\section{Non-adherence to long-term medications}

Two methods to measure refill adherence were used, depending on the objectives of study (295). The CMA method used in study IV is likely to overestimate the medication adherence to a multidrug therapy, especially during a short study period. This method was used, as the objective was to include the oversupply of medications and to account for the real amount of available medications.

Studies III and IV did not allow assessing primary non-adherence, i.e. persons who were prescribed medications but never refilled them (296). Nevertheless, only 3.1\% of those with diagnosed essential hypertension did not purchase any medication during the study period in study III, which may not affect the findings, while only persons who initiated their medications were included in study IV. Furthermore, in the two studies, patients prescribed multidose dispensing were excluded, because of the absence of prescribed daily doses. However, more research is needed to evaluate adherence in persons using multidose dispensing, especially with regards to concerns about the appropriate use of medications in patients using multidose dispensing (203).

One strength of study III was the combination of a sensitive and a specific method to detect nonadherent persons to a multidrug therapy. Non-adherence to any medication may be practically useful to screen non-adherent patients to any antihypertensive medications while non-adherence to the full therapy regimen, being more specific, may better detect behaviour changes (155). Yet, the method to assess adherence to the full therapy regimen may underestimate adherence when persons switch appropriately to another antihypertensive class. However, there is no gold standard method to assess the adherence to a full multidrug therapy for chronic conditions. 
The common threshold of $80 \%$ was used to define non-adherence. However, the validity of this value is questionable since the association between non-adherence and STEs depends also on the medication's pharmacological characteristics, such as the medication plasma halftime (286). For example, taking $90 \%$ of the prescribed doses of the angiotensin-converting enzyme inhibitor enalapril is predicted to be inappropriate, while taking $50 \%$ of the prescribed doses of the calcium channel blocker amlodipine may still give close to the full therapeutic effect (286). Moreover, the threshold of CMA or PDC of $80 \%$ can describe very different patterns of medication-refill behaviour (286). Therefore, more research is needed to standardise the measurement methods of adherence in order to facilitate the comparisons between studies $(153,154)$. Other measures of refill adherence, such as adherence trajectories have gained interest recently as they were found to better predict clinical outcomes (297).

Similar to register-based studies, studies II-IV reported medication prescription and refill patterns, considering them as a proxy of the actual use of medications by patients. Prescribed medications dispensed before the study period and not taken as prescribed or discontinued because of nonadherence were not taken into account in the analyses of PIPs in study II. Similarly, the assumption of medication consumption may overestimate adherence in studies III and IV. Nevertheless, the act of refilling a medication reflects a patient's active decision to continue with medication, and refill adherence is correlated with other measures of adherence (151).

\section{Assessment of drug-related morbidities}

One strength of study II was the access to the medical records, including medical histories, and prescription data of patients across care settings. However, the retrospective design was challenging, but was the only possibility since a prospective design would not be feasible. The method used to assess ADRs was based on biological and clinical data, and allowed the detection of ADRs that were not perceived or reported as such in the medical records. However, symptoms of ADRs not reported in the medical records could not be detected.

The detection of STEs in study III was based on BP measurements in healthcare settings. However, the different practices used to measure BP (298), and the risk of white-coat hypertension (299), may have affected the findings. Moreover, since the objective of this thesis was to assess the association of non-adherence with elevated BP, the visit with the highest BP values was considered, and the findings may therefore not be generalisable for patients with labile BP. Yet, the method of 
study III may serve as an impetus for larger studies to better understand the relationship between refill adherence and clinical outcomes in real-life settings.

Respondents to the survey self-assessed the medications causing their perceived STEs and ADRs. The questionnaire was tested for content and face validity. However, the administered questions may not be sensitive enough for STEs of asymptomatic conditions. It has been found that patients report more adverse health outcomes when their caregivers ask them specifically about their medication and to detail the symptoms of adverse outcomes (300). In fact, the population of study IV was identified from the respondents of a larger survey on all DRMs, and respondents have mainly reported symptomatic STEs and ADRs (195). Furthermore, a recall bias is to be considered as respondents may not have reported some accepted ADRs (300). Yet, considering patients with chronic conditions, often self-administering a multidrug therapy, and renewing their medications without meeting their physician, this finding may reflect a lack of information received by persons for ADRs and STEs of medications for chronic cardiovascular conditions. Thus, there may be a need for better communication and adaptation of information given by caregivers, especially for individuals with chronic conditions.

\section{Statistical considerations}

To study the association between PIPs and ADRs, the regression model was adjusted with known factors associated with PIPs and ADRs. However, some confounders might have been undetected or not included, because of their unavailability. The new STOPP criteria were purposefully not considered in the sensitivity analysis as they are based on new recommendations that may be irrelevant to apply to prescriptions in 2008.

In study II, regression models were adjusted with known patient factors associated with medication non-adherence. However, the nature of data did not allow investigating other factors, such as patients' understanding of side effects, and other healthcare system factors (147). Other possible sources of bias include the use of ICD codes to identify comorbidities (301). Moreover, the small sample size did not allow adjusting for a larger number of variables as, non-cardiovascular comorbidities. Healthcare resource use was assessed simultaneously with adherence, hindering establishing temporality as non-adherence might have led to increasing morbidity and higher medical care use in some patients. 


\section{CONCLUSIONS}

The findings of this thesis suggest that IUM is the cause of about half of ADRs occurring in inpatients and outpatients.

Potentially inappropriate prescriptions affected about half of elderly patients across care settings, and were associated with increased odds to experience ADRs, in particular nervous and vascular disorders and falls. Therefore, decreasing PIPs could contribute towards ADR prevention.

Sociodemographic factors (younger age and the lowest income) were associated with nonadherence to any prescribed medication while clinical factors (using specialised healthcare, having multiple medications, and being a new user) were associated with non-adherence to the full multidrug therapy. Thus, the findings of this thesis improve the understanding of the barriers to adherence to a multidrug therapy for tailoring interventions to improve adherence to patients' needs. Monitoring refilled medications prior to healthcare visits may assist in interpreting observed STEs. Yet, the absence of an association between long-term measures of non-adherence and STEs advocates for better comprehension of this association in clinical practice.

Undersupply and oversupply of long-term prescribed medications were common, but this inadequate refill behaviour of long-term medications was not associated with perceived DRMs, probably contributed by the low number of perceived ADRs and STEs. Thus, a better understanding of patients' refill behaviour and their perceived adverse outcomes from their longterm medications is needed.

The increasing number of the elderly and persons with chronic conditions constitute a significant challenge for the healthcare. The high prevalence of PIPs among the elderly, the commonness of both non-adherence and oversupply of long-term therapies, and the high proportion of ADRs due to IUM, reveal a significant potential for improvements of medication use and outcomes. 


\section{FUTURE RESEARCH}

Based on the findings of this thesis, areas of interest for future research have been identified. More research is needed on ADRs due to IUM occurring in primary care and in the community, since previous research was mainly conducted in hospital settings.

Future research should focus on studying the applicability of PIPs criteria in clinical practice, and whether improving the quality of prescribing is translated into improved health outcomes of the elderly. Both patients' preferences and physicians' views must be considered in order to understand the reasons of inappropriate prescribing despite the availability of safer alternatives in order to efficiently target future interventions to improve the quality of prescribing in the elderly. Further, standardising the instruments to evaluate the quality of prescribing would enhance the comparison between studies and the knowledge on medications commonly inappropriately prescribed in different settings.

Since a significant proportion of persons with chronic conditions use a multidrug therapy, considering the use of multiple medications and homogenising the definitions of adherence to a multidrug therapy would improve the understanding of adherence and related barriers. Such improved understanding may facilitate tailoring interventions to improve adherence to patients' needs.

Finally, future research on the association between non-adherence and DRMs should also inspect other factors that may influence this association such as the healthy adherer effect and patients' knowledge about their medications, and consider both clinical and patient perspectives. 


\section{ACKNOWLEDGEMENT}

The research of thesis was part of DRUMS project: Drug-related morbidity in Sweden Prevalence, preventability and costs. The financial support of: The National Corporation of Swedish Pharmacies (Apoteket AB), Linköping University, Östergötland County Council, The Nordic School of Public Health NHV and the Region Västra Götaland is gratefully acknowledged. Furthermore, I am grateful to The European Association for Clinical Pharmacology and Therapeutics, Elisabeth and Alfred Ahlqvists stiftelse and Apotekare Gunnar Hylténs stiftelse for their support to attend and present my research at conferences.

I would like to express my sincere gratitude to all the people who have supported me and contributed to make this thesis possible:

Main supervisor, Staffan Hägg, for your constant guidance, support and motivation. Your deep knowledge of pharmacoepidemiology has been extremely beneficial to me. Thank you Staffan for your trust and for being such a humble and great tutor!

Co-supervisor, Max Petzold, for your valuable advice on statistics and guidance in methodology and for your availability even in times when you have been extremely busy in faraway parts of the world.

Co-supervisor and friend, Katja Hakkarainen. You have been a great travel mate in my journey toward this doctoral thesis. Thank you for your constructive and detailed comments and inspiring discussions. Thank you for caring about my children when I was extremely busy. I hope we will have the opportunity to collaborate and do more things together in the future.

Co-author and friend, Hanna Gyllensten for your valuable help in understanding the Swedish healthcare system, for your availability whenever I needed your support, and for your eternal good mood.

Co-author and project leader of the survey study, Karolina Andersson Sundell. Your competence in quantitative research methods and your focus on details have been a great source of learning.

Co-authors Anna Jönsson, for the good collaboration and for initiating the medical record study. 
All the other researchers who contributed to DRUMS project: Daniel Alström, Anders Carlsten, Ingela Jacobsson, Mats Klingberg, Josefina Lindstén, Ellinor Ottosson, Johnny Pettersson, Clas Rehnberg, Parshin Saadatirad, Staffan Svensson, Karin Tunér, Annika Yeiter, and Tatiana Zverkova Sandström.

Björn Wettermark, Mikael Hoffmann, Ylva Böttiger, Henrik Lövborg and Curt Peterson for your constructive comments during mid-term and final seminars, and to Thomas Bradley, for giving me the opportunity to present and discuss my research within your group.

My colleagues at the division of Drug Research at Linköping University, in particular Madeleine Örlin for your precious administrative help that made many things easier with the distance. Thank you Madeleine!

My former fellow doctoral students at the Nordic School of Public Health for your support and sincere friendship in ups and in downs, and all the staff for the nice work atmosphere.

Tove Hedenrud at the Section of Social Medicine, University of Gothenburg for interesting and educational seminars and your encouragements.

The personnel from the World Health Organization Collaborating Center for International Drug Monitoring in Morocco, in particular, Professor Rachida Souleymani, Loubna Alj and Doctor Raja Benkirane. It has been a privilege to visit your centre and appreciate your great work in promoting medication safety in African countries. Thank you for warmly welcoming me. I hope to have the possibility to collaborate with you in the future.

My friend, Mariam Elbornsson for her advices and precious guidance on the prescribing recommendations in Sweden.

My friends in Sweden and in various parts of the world for the good times spent together. Many things would not be possible to accomplish for a women with young children without your support and encouragements.

My in-laws for caring about me and for always warmly welcoming me and my family whenever we needed to load our batteries and escape the Swedish weather.

My family, in particular my cousins, for all the unique moments we spend together, for long and deep talks about life and for many moments of laughs. A special thought to my dear aunts for always being there and caring for me. 
My dear brothers and sister, you and your families are the lights of my life. Although the distance, you have always been present. Feeling and knowing that you are here for me, make me manage anything.

My wonderful parents papa Omar and mama Zakia, I do not have enough words to express my gratitude. Thank you for your endless love, for teaching me that nothing is impossible, that success in life is not only about professional achievements and for always encouraging me to embark on new challenges in life.

My beloved husband Mourad and my adorable children, Mouna, Yousra and Ilyes. Thank you for the joy you bring to my life, for tolerating my very long working hours and me being often absent minded. You are my solid rock and you are everything to me. 


\section{REFERENCES}

1. Vrijens B, De Geest S, Hughes DA, Przemyslaw K, Demonceau J, Ruppar T, et al. A new taxonomy for describing and defining adherence to medications. Br J Clin Pharmacol. 2012 May;73(5):691-705

2. World Health Organization. International drug monitoring: the role of national centres. Technical report series. Geneva: World Health Organization; 1972

3. Hepler CD, Strand LM. Opportunities and responsibilities in pharmaceutical care. Am J Hosp Pharm. 1990;47(3):533-43

4. Hanlon JT, Schmader KE, Ruby CM, Weinberger M. Suboptimal prescribing in older inpatients and outpatients. J Am Geriatr Soc. 2001;49(2):200-9

5. Hanlon JT, Handler SM, Maher RL, Schmader KE. Geriatric pharmacotherapy and polypharmacy In: Brocklehurst's Textbook of Geriatric Medicine. 7th ed, UK: Churchill Livingstone: Fillit H, Rockwood K, Woodhouse K; 2010. 880-5

6. Weitoft GR, Ericsson O, Fastbom J. Prescription drugs: Health in Sweden: The National Public Health Report 2012. Chapter 18. Scand J Public Health. 2012;40(9 Suppl):293-304

7. Knopf H, Grams D. Medication use of adults in Germany: Results of the German Health Interview and Examination Survey for Adults. Bundesgesundheitsblatt Gesundheitsforschung Gesundheitsschutz. 2013;56(5-6):868-77

8. Zhong W, Maradit-Kremers H, St Sauver JL, Yawn BP, Ebbert JO, Roger VL, et al. Age and sex patterns of drug prescribing in a defined American population. Mayo Clin Proc. 2013;88(7):697-707

9. Rotermann M, Sanmartin C, Hennessy D, Arthur M. Prescription medication use by Canadians aged 6 to 79. Health Rep. 2014;25(6):3-9

10. Scholes S, Faulding S, Mindell J. Use of Prescribed Medicines: The Health and Social Care Information. London. 2014

11. Looking back on the millennium in medicine. N Engl J Med. 2000;342(1):42-9

12. Weisfeldt ML, Zieman SJ. Advances in the prevention and treatment of cardiovascular disease. Health Aff. 2007;26(1):25-37

13. De Vries EN, Ramrattan MA, Smorenburg SM, Gouma DJ, Boermeester MA. The incidence and nature of in-hospital adverse events: a systematic review. Qual Saf Health Care.

2008;17(3):216-23

14. Merten H, Zegers M, de Bruijne MC, Wagner C. Scale, nature, preventability and causes of adverse events in hospitalised older patients. Age Ageing. 2013;42(1):87-93 
15. Castellano-Zurera MM, Nunez-Garcia D, Carrasco-Peralta JA, Torres-Olivera A. Patient safety risks in primary health care: identification and prevention of adverse events. Rev Calid Asist. 2012;27(6):319-25

16. Leape LL, Brennan TA, Laird N, Lawthers AG, Localio AR, Barnes BA, et al. The nature of adverse events in hospitalized patients. Results of the Harvard Medical Practice Study II. N Engl J Med. 1991;324(6):377-84

17. Morimoto T, Gandhi TK, Seger AC, Hsieh TC, Bates DW. Adverse drug events and medication errors: detection and classification methods. Qual Saf Health Care. 2004;13(4):306-14

18. Van Mil JW, Westerlund LO, Hersberger KE, Schaefer MA. Drug-related problem classification systems. Ann Pharmacother. 2004;38(5):859-67

19. Pintor-Marmol A, Baena MI, Fajardo PC, Sabater-Hernandez D, Saez-Benito L, GarciaCardenas MV, et al. Terms used in patient safety related to medication: a literature review. Pharmacoepidemiol Drug Saf. 2012;21(8):799-809

20. Johnson JA, Bootman JL. Drug-related morbidity and mortality. A cost-of-illness model. Arch Intern Med. 1995;155(18):1949-56

21. Hakkarainen KM, Gyllensten H, Jonsson AK, Andersson Sundell K, Petzold M, Hagg S. Prevalence, nature and potential preventability of adverse drug events - a population-based medical record study of 4970 adults. Br J Clin Pharmacol. 2014;78(1):170-83

22. Raschetti R, Morgutti M, Menniti-Ippolito F, Belisari A, Rossignoli A, Longhini P, et al. Suspected adverse drug events requiring emergency department visits or hospital admissions. Eur J Clin Pharmacol. 1999;54(12):959-63

23. Al-Olah YH, Al Thiab KM. Admissions through the emergency department due to drugrelated problems. Ann Saudi Med. 2008;28(6):426-9

24. Hallas J, Gram LF, Grodum E, Damsbo N, Brosen K, Haghfelt T, et al. Drug related admissions to medical wards: a population based survey. Br J Clin Pharmacol. 1992;33(1):61-8

25. Nelson KM, Talbert RL. Drug-related hospital admissions. Pharmacotherapy. 1996;16(4):701-7

26. Zargarzadeh AH, Emami MH, Hosseini F. Drug-related hospital admissions in a generic pharmaceutical system. Clin Exp Pharmacol Physiol. 2007;34(5-6):494-8

27. Baena MI, Faus MJ, Fajardo PC, Luque FM, Sierra F, Martinez-Olmos J, et al. Medicinerelated problems resulting in emergency department visits. Eur J Clin Pharmacol. 2006;62(5):38793

28. Gandhi TK, Burstin HR, Cook EF, Puopolo AL, Haas JS, Brennan TA, et al. Drug complications in outpatients. J Gen Intern Med. 2000;15(3):149-54 
29. De Smedt RH, Haaijer-Ruskamp FM, Groenier KH, van der Meer K, Jaarsma T. Perceived adverse drug events in heart failure: patients' perception and related factors. J Cardiovasc Nurs. 2011;26(3):250-60

30. Sorensen L, Stokes JA, Purdie DM, Woodward M, Roberts MS. Medication management at home: medication-related risk factors associated with poor health outcomes. Age Ageing. 2005;34(6):626-32

31. Wester K, Jonsson AK, Spigset O, Druid H, Hagg S. Incidence of fatal adverse drug reactions: a population based study. Br J Clin Pharmacol. 2008;65(4):573-9

32. Lazarou J, Pomeranz BH, Corey PN. Incidence of adverse drug reactions in hospitalized patients: a meta-analysis of prospective studies. JAMA. 1998;279(15):1200-5

33. Buajordet I, Ebbesen J, Erikssen J, Brors O, Hilberg T. Fatal adverse drug events: the paradox of drug treatment. J Intern Med. 2001;250(4):327-41

34. Gyllensten H, Hakkarainen KM, Hagg S, Carlsten A, Petzold M, Rehnberg C, et al. Economic impact of adverse drug events--a retrospective population-based cohort study of 4970 adults. PLoS One. 2014;9(3):e92061

35. Ernst FR, Grizzle AJ. Drug-related morbidity and mortality: updating the cost-of-illness model. J Am Pharm Assoc. 2001;41(2):192-9

36. Kanjanarat P, Winterstein AG, Johns TE, Hatton RC, Gonzalez-Rothi R, Segal R. Nature of preventable adverse drug events in hospitals: a literature review. Am J Health Syst Pharm. 2003;60(17):1750-9

37. Krahenbuhl-Melcher A, Schlienger R, Lampert M, Haschke M, Drewe J, Krahenbuhl S. Drug-related problems in hospitals: a review of the recent literature. Drug Saf. 2007;30(5):379407

38. Tache SV, Sonnichsen A, Ashcroft DM. Prevalence of adverse drug events in ambulatory care: a systematic review. Ann Pharmacother. 2011;45(7-8):977-89

39. Leendertse AJ, Visser D, Egberts AC, van den Bemt PM. The relationship between study characteristics and the prevalence of medication-related hospitalizations: a literature review and novel analysis. Drug Saf. 2010;33(3):233-44

40. Krahenbuhl-Melcher A, Schlienger R, Lampert M, Haschke M, Drewe J, Krahenbuhl S. Drug-related problems in hospitals: a review of the recent literature. Drug Saf. 2007;30(5):379407

41. Cano FG, Rozenfeld S. Adverse drug events in hospitals: a systematic review. Cad Saude Publica. 2009;25(3):360-72

42. Manias E. Detection of medication-related problems in hospital practice: a review. Br J Clin Pharmacol. 2013;76(1):7-20 
43. Kongkaew C, Noyce PR, Ashcroft DM. Hospital admissions associated with adverse drug reactions: a systematic review of prospective observational studies. Ann Pharmacother.

2008;42(7):1017-25

44. Nivya K, Sri Sai Kiran V, Ragoo N, Jayaprakash B, Sonal Sekhar M. Systemic review on drug related hospital admissions - A pubmed based search. Saudi Pharm J. 2015;23(1):1-8

45. Al Hamid A, Ghaleb M, Aljadhey H, Aslanpour Z. A systematic review of hospitalization resulting from medicine-related problems in adult patients. Br J Clin Pharmacol. 2014;78(2):20217

46. Ferner RE. Harms from medicines: inevitable, in error or intentional. Br J Clin Pharmacol. 2014;77(3):403-9

47. Goettler M, Schneeweiss S, Hasford J. Adverse drug reaction monitoring--cost and benefit considerations. Part II: cost and preventability of adverse drug reactions leading to hospital admission. Pharmacoepidemiol Drug Saf. 1997;6(3):79-90

48. Edwards IR, Aronson JK. Adverse drug reactions: definitions, diagnosis, and management. Lancet. 2000;356(9237):1255-9

49. Ferner RE, Aronson JK. Preventability of drug-related harms - part I: a systematic review. Drug Saf. 2010;33(11):985-94

50. Salvi F, Marchetti A, D'Angelo F, Boemi M, Lattanzio F, Cherubini A. Adverse drug events as a cause of hospitalization in older adults. Drug Saf. 2012;35(1):29-45

51. Veehof LJ, Stewart RE, Meyboom-de Jong B, Haaijer-Ruskamp FM. Adverse drug reactions and polypharmacy in the elderly in general practice. Eur J Clin Pharmacol. 1999;55(7):533-6

52. Reason B, Terner M, Moses McKeag A, Tipper B, Webster G. The impact of polypharmacy on the health of Canadian seniors. Fam Pract. 2012;29(4):427-32

53. Einarson TR. Drug-related hospital admissions. Ann Pharmacother. 1993;27(7-8):832-40

54. Beijer HJ, de Blaey CJ. Hospitalisations caused by adverse drug reactions: a meta-analysis of observational studies. Pharm World Sci. 2002;24(2):46-54

55. Patel RS, Marcum ZA, Peron EP, Ruby CM. Prevalence of and factors associated with therapeutic failure-related hospitalizations in the elderly. Consult Pharm. 2014;29(6):376-86

56. Marcum ZA, Pugh MJ, Amuan ME, Aspinall SL, Handler SM, Ruby CM, et al. Prevalence of potentially preventable unplanned hospitalizations caused by therapeutic failures and adverse drug withdrawal events among older veterans. J Gerontol A Biol Sci Med Sci. 2012;67(8):867-74

57. Wright RM, Sloane R, Pieper CF, Ruby-Scelsi C, Twersky J, Schmader KE, et al. Underuse of indicated medications among physically frail older US veterans at the time of hospital discharge: results of a cross-sectional analysis of data from the Geriatric Evaluation and Management Drug Study. Am J Geriatr Pharmacother. 2009;7(5):271-80 
58. World Health Organisation. Adherence to long-term therapies: Evidence for action. Geneva: World Health Organization; 2003

59. Reynolds J, Heysell SK. Understanding pharmacokinetics to improve tuberculosis treatment outcome. Expert Opin Drug Metab Toxicol. 2014;10(6):813-23

60. Franceschi A, Tuccori M, Bocci G, Vannozzi F, Di Paolo A, Barbara C, et al. Drug therapeutic failures in emergency department patients. A university hospital experience. Pharmacol Res. 2004;49(1):85-91

61. Wolf-Maier K, Cooper RS, Kramer H, Banegas JR, Giampaoli S, Joffres MR, et al. Hypertension treatment and control in five European countries, Canada, and the United States. Hypertension. 2004;43(1):10-7

62. World Health Organization. Innovative Care for Chronic Conditions: Building Blocks for Action. Geneva: World Health Organization; 2002

63. Lim GB. Global burden of cardiovascular disease. Nat Rev Cardiol. 2013;10(2):59

64. Moore J. Hypertension: catching the silent killer. Nurse Pract. 2005;30(10):16-8, 23-4, 26-7

65. Tolonen H, Keil U, Ferrario M, Evans A, WHO MONICA Project. Prevalence, awareness and treatment of hypercholesterolaemia in 32 populations: results from the WHO MONICA Project. Int J Epidemiol. 2005;34(1):181-92

66. World Health Organization. Managing chronic conditions. Experience in eight countries. Copenhagen: World Health Organization; 2008

67. Hu D, Fu P, Xie J, Chen CS, Yu D, Whelton PK, et al. Increasing prevalence and low awareness, treatment and control of diabetes mellitus among Chinese adults: the InterASIA study. Diabetes Res Clin Pract. 2008;81(2):250-7

68. Whelton PK, He J, Muntner P. Prevalence, awareness, treatment and control of hypertension in North America, North Africa and Asia. J Hum Hypertens. 2004;18(8):545-51

69. Lindblad U, Ek J, Eckner J, Larsson CA, Shan G, Rastam L. Prevalence, awareness, treatment, and control of hypertension: rule of thirds in the Skaraborg project. Scand J Prim Health Care. 2012;30(2):88-94

70. World Health Organization. Global status report on non-communicable diseases. Geneva: World Health Organization; 2014

71. Choudhry NK, Glynn RJ, Avorn J, Lee JL, Brennan TA, Reisman L, et al. Untangling the relationship between medication adherence and post-myocardial infarction outcomes: medication adherence and clinical outcomes. Am Heart J. 2014;167(1):51-8

72. Krousel-Wood M, Thomas S, Muntner P, Morisky D. Medication adherence: a key factor in achieving blood pressure control and good clinical outcomes in hypertensive patients. Curr Opin Cardiol. 2004;19(4):357-62 
73. De Geest S, Ruppar T, Berben L, Schonfeld S, Hill MN. Medication non-adherence as a critical factor in the management of presumed resistant hypertension: a narrative review. EuroIntervention. 2014;9(9):1102-9

74. Brown MT, Bussell JK. Medication adherence: WHO cares? Mayo Clin Proc. 2011 Apr;86(4):304-14

75. World Health Organization. Promoting rational use of medicines: Core Components - WHO policy perspectives on medicines. Geneva: World Health Organization; 2002

76. Committee on Identifying and Preventing Medication Errors. Preventing medication errors: Quality Chasm Series. Washington DC: The National Academies Press; 2007

77. Hepler C, Segal R. Preventing medication errors and improving drug therapy outcomes. Florida: CRC Press; 2003

78. Reason J. Human error: models and management. BMJ. 2000;320(7237):768-70

79. Chiatti C, Bustacchini S, Furneri G, Mantovani L, Cristiani M, Misuraca C, et al. The economic burden of inappropriate drug prescribing, lack of adherence and compliance, adverse drug events in older people: a systematic review. Drug Saf. 2012;35(1):73-87

80. Bradley MC, Fahey T, Cahir C, Bennett K, O'Reilly D, Parsons C, et al. Potentially inappropriate prescribing and cost outcomes for older people: a cross-sectional study using the Northern Ireland Enhanced Prescribing Database. Eur J Clin Pharmacol. 2012;68(10):1425-33

81. Brown C, Hofer T, Johal A, Thomson R, Nicholl J, Franklin BD, et al. An epistemology of patient safety research: a framework for study design and interpretation. Part 1. Conceptualising and developing interventions. Qual Saf Health Care. 2008;17(3):158-62

82. Thomsen LA, Winterstein AG, Sondergaard B, Haugbolle LS, Melander A. Systematic review of the incidence and characteristics of preventable adverse drug events in ambulatory care. Ann Pharmacother. 2007;41(9):1411-26

83. Patel P, Zed PJ. Drug-related visits to the emergency department: how big is the problem? Pharmacotherapy. 2002;22(7):915-23

84. Howard RL, Avery AJ, Slavenburg S, Royal S, Pipe G, Lucassen P, et al. Which drugs cause preventable admissions to hospital? A systematic review. Br J Clin Pharmacol. 2007;63(2):136-47

85. Morris CJ, Cantrill JA, Hepler CD, Noyce PR. Preventing drug-related morbiditydetermining valid indicators. Int J Qual Health Care. 2002;14(3):183-98

86. European Directorate for the Quality of Medicines and HealthCare Pharmaceutical care policies and practices for a safer, more responsible and cost-effective health system. Council of Europe; 2012

87. Kohn LT, Corrigan JM, Donaldson MS. To err is human: Building a safer health system Washington, DC: National Academy Press; 2000 
88. Bates DW, Larizgoitia I, Prasopa-Plaizier N, Jha AK, Research Priority Setting Working Group of the WHO World Alliance for Patient Safety. Global priorities for patient safety research. BMJ 2009; 14(338):1775

89. Expert Group on Safe Medication Practices. Creation of a better medication safety culture in Europe: Building up safe medication practices. Council of Europe; 2006

90. National Board of Health and Welfare. Current status of patient safety 2013 [n Swedish: Lägesrapport inom patientsäkerhetsområdet 2013]. Västerås; 2013

91. US Agency for Healthcare Research and Quality. Patient Safety and Quality Improvement Act [109-41]; 2005

92. Care Quality Commission. Guidance about compliance. Essential standards of quality and safety. Care Quality Commission UK; 2010

93. Winterstein AG, Sauer BC, Hepler CD, Poole C. Preventable drug-related hospital admissions. Ann Pharmacother. 2002;36(7-8):1238-48

94. Gallagher P, Barry P, O'Mahony D. Inappropriate prescribing in the elderly. J Clin Pharm Ther. 2007;32(2):113-21

95. Cahir C, Bennett K, Teljeur C, Fahey T. Potentially inappropriate prescribing and adverse health outcomes in community dwelling older patients. Br J Clin Pharmacol. 2014;77(1):201-10

96. Lund BC, Carnahan RM, Egge JA, Chrischilles EA, Kaboli PJ. Inappropriate prescribing predicts adverse drug events in older adults. Ann Pharmacother. 2010;44(6):957-63

97. Budnitz DS, Shehab N, Kegler SR, Richards CL. Medication use leading to emergency department visits for adverse drug events in older adults. Ann Intern Med. 2007;147(11):755-65

98. Klarin I, Wimo A, Fastbom J. The association of inappropriate drug use with hospitalisation and mortality: a population-based study of the very old. Drugs Aging. 2005;22(1):69-82

99. Lau DT, Kasper JD, Potter DE, Lyles A, Bennett RG. Hospitalization and death associated with potentially inappropriate medication prescriptions among elderly nursing home residents. Arch Intern Med. 2005;165(1):68-74

100. Al-Omar HA, Al-Sultan MS, Abu-Auda HS. Prescribing of potentially inappropriate medications among the elderly population in an ambulatory care setting in a Saudi military hospital: trend and cost. Geriatr Gerontol Int. 2013;13(3):616-21

101. Opondo D, Eslami S, Visscher S, de Rooij SE, Verheij R, Korevaar JC, et al. Inappropriateness of medication prescriptions to elderly patients in the primary care setting: a systematic review. PLoS One. 2012;7(8):e43617

102. Mangoni AA, Jackson SH. Age-related changes in pharmacokinetics and pharmacodynamics: basic principles and practical applications. Br J Clin Pharmacol. 2004;57(1):6-14 
103. Olsson J, Bergman A, Carlsten A, Oke T, Bernsten C, Schmidt IK, et al. Quality of drug prescribing in elderly people in nursing homes and special care units for dementia: a crosssectional computerized pharmacy register analysis. Clin Drug Investig. 2010;30(5):289-300

104. Konrat C, Boutron I, Trinquart L, Auleley GR, Ricordeau P, Ravaud P.

Underrepresentation of elderly people in randomised controlled trials. The example of trials of 4 widely prescribed drugs. PLoS One. 2012;7(3):e33559

105. O'Mahony D, Gallagher PF. Inappropriate prescribing in the older population: need for new criteria. Age Ageing. 2008;37(2):138-41

106. Dimitrow MS, Airaksinen MS, Kivela SL, Lyles A, Leikola SN. Comparison of prescribing criteria to evaluate the appropriateness of drug treatment in individuals aged 65 and older: a systematic review. J Am Geriatr Soc. 2011;59(8):1521-30

107. Spinewine A, Schmader KE, Barber N, Hughes C, Lapane KL, Swine C, et al. Appropriate prescribing in elderly people: how well can it be measured and optimised? Lancet.

2007;370(9582):173-84

108. Corsonello A, Onder G, Abbatecola AM, Guffanti EE, Gareri P, Lattanzio F. Explicit criteria for potentially inappropriate medications to reduce the risk of adverse drug reactions in elderly people: from Beers to STOPP/START criteria. Drug Saf. 2012;35(1):21-8

109. Chang CB, Chan DC. Comparison of published explicit criteria for potentially inappropriate medications in older adults. Drugs Aging. 2010;27(12):947-57

110. O'Connor MN, Gallagher P, O'Mahony D. Inappropriate prescribing: criteria, detection and prevention. Drugs Aging. 2012;29(6):437-52

111. Fastbom J, Johnell K. National indicators for quality of drug therapy in older persons: the Swedish experience from the first 10 years. Drugs Aging. 2015;32(3):189-99

112. Kaufmann CP, Tremp R, Hersberger KE, Lampert ML. Inappropriate prescribing: a systematic overview of published assessment tools. Eur J Clin Pharmacol. 2014;70(1):1-11

113. Beers MH, Ouslander JG, Rollingher I, Reuben DB, Brooks J, Beck JC. Explicit criteria for determining inappropriate medication use in nursing home residents. UCLA Division of Geriatric Medicine. Arch Intern Med. 1991;151(9):1825-32

114. American Geriatrics Society 2012 Beers Criteria Update Expert Panel. American Geriatrics Society updated Beers Criteria for potentially inappropriate medication use in older adults. J Am Geriatr Soc. 2012;60(4):616-31

115. Pozzi C, Lapi F, Mazzaglia G, Inzitari M, Boncinelli M, Geppetti P, et al. Is suboptimal prescribing a risk factor for poor health outcomes in community-dwelling elders? The ICARe Dicomano study. Pharmacoepidemiol Drug Saf. 2010;19(9):954-60

116. Barnett K, McCowan C, Evans JM, Gillespie ND, Davey PG, Fahey T. Prevalence and outcomes of use of potentially inappropriate medicines in older people: cohort study stratified by residence in nursing home or in the community. BMJ Qual Saf. 2011;20(3):275-81 
117. Gallagher P, O'Mahony D. STOPP (Screening Tool of Older Persons' potentially inappropriate Prescriptions): application to acutely ill elderly patients and comparison with Beers' criteria. Age Ageing. 2008;37(6):673-9

118. Ruggiero C, Dell'Aquila G, Gasperini B, Onder G, Lattanzio F, Volpato S, et al. Potentially inappropriate drug prescriptions and risk of hospitalization among older, Italian, nursing home residents: the ULISSE project. Drugs Aging. 2010;27(9):747-58

119. Gallagher P, Ryan C, Byrne S, Kennedy J, O'Mahony D. STOPP (Screening Tool of Older Person's Prescriptions) and START (Screening Tool to Alert doctors to Right Treatment). Consensus validation. Int J Clin Pharmacol Ther. 2008;46(2):72-83

120. Liu CL, Peng LN, Chen YT, Lin MH, Liu LK, Chen LK. Potentially inappropriate prescribing (IP) for elderly medical inpatients in Taiwan: a hospital-based study. Arch Gerontol Geriatr. 2012;55(1):148-51

121. Gallagher P, Lang PO, Cherubini A, Topinkova E, Cruz-Jentoft A, Montero Errasquin B, et al. Prevalence of potentially inappropriate prescribing in an acutely ill population of older patients admitted to six European hospitals. Eur J Clin Pharmacol. 2011;67(11):1175-88

122. Pyszka LL, Seys Ranola TM, Milhans SM. Identification of inappropriate prescribing in geriatrics at a Veterans Affairs hospital using STOPP/START screening tools. Consult Pharm. 2010;25(6):365-73

123. Oliveira MG, Amorim WW, de Jesus SR, Heine JM, Coqueiro HL, Passos LC. A comparison of the Beers and STOPP criteria for identifying the use of potentially inappropriate medications among elderly patients in primary care. J Eval Clin Pract. 2015;21(2):320-5

124. Garcia-Gollarte F, Baleriola-Julvez J, Ferrero-Lopez I, Cruz-Jentoft AJ. Inappropriate drug prescription at nursing home admission. J Am Med Dir Assoc. 2012;13(1):83.e9-15

125. Vermeulen Windsant-van den Tweel AM, Verduijn MM, Derijks HJ, van Marum RJ. Detection of inappropriate medication use in the elderly; will the STOPP and START criteria become the new Dutch standards? Ned Tijdschr Geneeskd. 2012;156(40):5076

126. Cruz-Jentoft AJ. New therapies for an ageing Europe. European Union Geriatric Medicine Society Malaga Congress. 2011

127. Johnell K, Fastbom J, Rosen M, Leimanis A. Inappropriate drug use in the elderly: A nationwide register-based study. Ann Pharmacother. 2007;41(7):1243-8

128. Morin L, Fastbom J, Laroche ML, Johnell K. Potentially inappropriate drug use in older people: a nationwide comparison of different explicit criteria for population-based estimates. $\mathrm{Br} \mathrm{J}$ Clin Pharmacol. 2015;80(2):315-24

129. Blalock SJ, Byrd JE, Hansen RA, Yamanis TJ, McMullin K, DeVellis BM, et al. Factors associated with potentially inappropriate drug utilization in a sample of rural communitydwelling older adults. Am J Geriatr Pharmacother. 2005;3(3):168-79 
130. Fialova D, Topinkova E, Gambassi G, Finne-Soveri H, Jonsson PV, Carpenter I, et al. Potentially inappropriate medication use among elderly home care patients in Europe. JAMA. 2005;293(11):1348-58

131. Aparasu RR, Mort JR. Inappropriate prescribing for the elderly: beers criteria-based review. Ann Pharmacother. 2000;34(3):338-46

132. Jano E, Aparasu RR. Healthcare outcomes associated with beers' criteria: a systematic review. Ann Pharmacother. 2007;41(3):438-47

133. Laroche M, Charmes J, Nouaille Y, Picard N, Merle L. Is inappropriate medication use a major cause of adverse drug reactions in the elderly? Br J Clin Pharmacol. 2007;63(2):177-86

134. Aronson JK. Compliance, concordance, adherence. Br J Clin Pharmacol. 2007;63(4):383-4

135. Gould E, Mitty E. Medication adherence is a partnership, medication compliance is not. Geriatr Nurs. 2010;31(4):290-8

136. Ho PM, Rumsfeld JS, Masoudi FA, McClure DL, Plomondon ME, Steiner JF, et al. Effect of medication nonadherence on hospitalization and mortality among patients with diabetes mellitus. Arch Intern Med. 2006;166(17):1836-41

137. Sokol MC, McGuigan KA, Verbrugge RR, Epstein RS. Impact of medication adherence on hospitalization risk and healthcare cost. Med Care. 2005;43(6):521-30

138. Vinker S, Alkalay A, Hoffman RD, Elhayany A, Kaiserman I, Kitai E. Long-term adherence to antihypertensive therapy: a survey in four primary care clinics. Expert Opin Pharmacother. 2008;9(8):1271-7

139. Ho PM, Magid DJ, Shetterly SM, Olson KL, Maddox TM, Peterson PN, et al. Medication nonadherence is associated with a broad range of adverse outcomes in patients with coronary artery disease. Am Heart J. 2008;155(4):772-9

140. Bramley TJ, Gerbino PP, Nightengale BS, Frech-Tamas F. Relationship of blood pressure control to adherence with antihypertensive monotherapy in 13 managed care organizations. J Manag Care Pharm. 2006;12(3):239-45

141. Schmittdiel JA, Uratsu CS, Karter AJ, Heisler M, Subramanian U, Mangione CM, et al. Why don't diabetes patients achieve recommended risk factor targets? Poor adherence versus lack of treatment intensification. J Gen Intern Med. 2008;23(5):588-94

142. Krigsman K, Melander A, Carlsten A, Ekedahl A, Nilsson JL. Refill non-adherence to repeat prescriptions leads to treatment gaps or to high extra costs. Pharm World Sci. 2007;29(1):19-24

143. Iuga AO, McGuire MJ. Adherence and health care costs. Risk Manag Healthc Policy. $2014 ; 7: 35-44$

144. Martin LR, Williams SL, Haskard KB, Dimatteo MR. The challenge of patient adherence. Ther Clin Risk Manag. 2005;1(3):189-99 
145. Rand CS. Measuring adherence with therapy for chronic diseases: implications for the treatment of heterozygous familial hypercholesterolemia. Am J Cardiol. 1993;72(10):68-74

146. Dunbar-Jacob J, Erlen JA, Schlenk EA, Ryan CM, Sereika SM, Doswell WM. Adherence in chronic disease. Annu Rev Nurs Res 2000;18:48-90

147. Osterberg L, Blaschke T. Adherence to medication. N Engl J Med. 2005;353(5):487-97

148. Vrijens B, Vincze G, Kristanto P, Urquhart J, Burnier M. Adherence to prescribed antihypertensive drug treatments: longitudinal study of electronically compiled dosing histories. BMJ. 2008;336(7653):1114-7

149. Wang PS, Benner JS, Glynn RJ, Winkelmayer WC, Mogun H, Avorn J. How well do patients report noncompliance with antihypertensive medications?: a comparison of self-report versus filled prescriptions. Pharmacoepidemiol Drug Saf. 2004;13(1):11-9

150. Baisley K, Baeten JM, Hughes JP, Donnell DJ, Wang J, Hayes R, et al. Summary measures of adherence using pill counts in two HIV prevention trials: The need for standardisation in reporting. AIDS Behav 2013;17(9):3108-19

151. Hansen RA, Kim MM, Song L, Tu W, Wu J, Murray MD. Comparison of methods to assess medication adherence and classify nonadherence. Ann Pharmacother. 2009;43(3):413-22

152. Andersson K, Melander A, Svensson C, Lind O, Nilsson JL. Repeat prescriptions: refill adherence in relation to patient and prescriber characteristics, reimbursement level and type of medication. Eur J Public Health. 2005;15(6):621-6

153. Vink NM, Klungel OH, Stolk RP, Denig P. Comparison of various measures for assessing medication refill adherence using prescription data. Pharmacoepidemiol Drug Saf.

2009;18(2):159-65

154. Raebel MA, Schmittdiel J, Karter AJ, Konieczny JL, Steiner JF. Standardizing terminology and definitions of medication adherence and persistence in research employing electronic databases. Med Care. 2013;51(8):11-21

155. Choudhry NK, Shrank WH, Levin RL, Lee JL, Jan SA, Brookhart MA, et al. Measuring concurrent adherence to multiple related medications. Am J Manag Care. 2009;15(7):457-64

156. Basak R, McCaffrey Iii DJ, Bentley JP, Przybyla SM, West-Strum D, Banahan BF. Adherence to multiple medications prescribed for a chronic disease: a methodological investigation. J Manag Care Pharm. 2014;20(8):815-23

157. Mancia G, Fagard R, Narkiewicz K, Redon J, Zanchetti A, Bohm M, et al. 2013 ESH/ESC guidelines for the management of arterial hypertension: the Task Force for the Management of Arterial Hypertension of the European Society of Hypertension (ESH) and of the European Society of Cardiology (ESC). Eur Heart J. 2013;34(28):2159-219

158. Johnson ML, Singh H. Patterns of antihypertensive therapy among patients with diabetes. J Gen Intern Med. 2005;20(9):842-6 
159. Van Wijk BL, Klungel OH, Heerdink ER, de Boer A. Refill persistence with chronic medication assessed from a pharmacy database was influenced by method of calculation. J Clin Epidemiol. 2006;59(1):11-7

160. Karve S, Cleves MA, Helm M, Hudson TJ, West DS, Martin BC. An empirical basis for standardizing adherence measures derived from administrative claims data among diabetic patients. Med Care. 2008;46(11):1125-33

161. Piette JD, Heisler M, Ganoczy D, McCarthy JF, Valenstein M. Differential medication adherence among patients with schizophrenia and comorbid diabetes and hypertension. Psychiatr Serv. 2007;58(2):207-12

162. Pladevall M, Williams LK, Potts LA, Divine G, Xi H, Lafata JE. Clinical outcomes and adherence to medications measured by claims data in patients with diabetes. Diabetes Care. 2004;27(12):2800-5

163. Fung V, Huang J, Brand R, Newhouse JP, Hsu J. Hypertension treatment in a medicare population: adherence and systolic blood pressure control. Clin Ther. 2007;29(5):972-84

164. Ishisaka DY, Jukes T, Romanelli RJ, Wong KS, Schiro TA. Disparities in adherence to and persistence with antihypertensive regimens: an exploratory analysis from a community-based provider network. J Am Soc Hypertens. 2012;6(3):201-9

165. Lagu T, Weiner MG, Eachus S, Tang SS, Schwartz JS, Turner BJ. Effect of patient comorbidities on filling of antihypertensive prescriptions. Am J Manag Care. 2009;15(1):24-30

166. Wamala S, Merlo J, Bostrom G, Hogstedt C, Agren G. Socioeconomic disadvantage and primary non-adherence with medication in Sweden. Int J Qual Health Care. 2007;19(3):134-40

167. Choudhry NK, Fischer MA, Avorn J, Liberman JN, Schneeweiss S, Pakes J, et al. The implications of therapeutic complexity on adherence to cardiovascular medications. Arch Intern Med. 2011;171(9):814-22

168. Hakonsen H, Eilertsen M, Borge H, Toverud EL. Generic substitution: additional challenge for adherence in hypertensive patients? Curr Med Res Opin. 2009;25(10):2515-21

169. Gray SL, Mahoney JE, Blough DK. Medication adherence in elderly patients receiving home health services following hospital discharge. Ann Pharmacother. 2001;35(5):539-45

170. Stroupe KT, Murray MD, Stump TE, Callahan CM. Association between medication supplies and healthcare costs in older adults from an urban healthcare system. J Am Geriatr Soc. 2000;48(7):760-8

171. Evans JM, Donnan PT, Morris AD. Adherence to oral hypoglycaemic agents prior to insulin therapy in type 2 diabetes. Diabet Med. 2002;19(8):685-8

172. Spoelstra JA, Stolk RP, Heerdink ER, Klungel OH, Erkens JA, Leufkens HG, et al. Refill compliance in type 2 diabetes mellitus: a predictor of switching to insulin therapy? Pharmacoepidemiol Drug Saf. 2003;12(2):121-7 
173. Thorpe CT, Johnson H, Dopp AL, Thorpe JM, Ronk K, Everett CM, et al. Medication oversupply in patients with diabetes. Res Social Adm Pharm. 2015;11(3):382-400

174. Stroupe KT, Teal EY, Tu W, Weiner M, Murray MD. Association of refill adherence and health care use among adults with hypertension in an urban health care system.

Pharmacotherapy. 2006;26(6):779-89

175. Thorpe CT, Bryson CL, Maciejewski ML, Bosworth HB. Medication acquisition and selfreported adherence in veterans with hypertension. Med Care. 2009;47(4):474-81

176. Dilokthornsakul P, Chaiyakunapruk N, Nimpitakpong P, Jeanpeerapong N, Jampachaisri K, Lee TA. Understanding medication oversupply and its predictors in the outpatient departments in Thailand. BMC Health Serv Res. 2014;14:408

177. Stroupe KT, Teal EY, Weiner M, Gradus-Pizlo I, Brater DC, Murray MD. Health care and medication costs and use among older adults with heart failure. Am J Med. 2004;116(7):443-50

178. Dilokthornsakul P, Chaiyakunapruk N, Nimpitakpong P, Jeanpeerapong N, Sruamsiri R. The effects of medication supply on hospitalizations and health-care costs in patients with chronic heart failure. Value Health. 2012;15(1):9-14

179. De Smet PA, Dautzenberg M. Repeat prescribing: scale, problems and quality management in ambulatory care patients. Drugs. 2004;64(16):1779-800

180. Christensen K, Doblhammer G, Rau R, Vaupel JW. Ageing populations: the challenges ahead. Lancet. 2009;374(9696):1196-208

181. United Nations, Department of Economic and Social Affairs. Population Division (2013). World Population Ageing 2013. ST/ESA/SER.A/348

182. Statistics Sweden. The future population of Sweden 2015-2060 [In Swedish: Sveriges framtida befolkning 2015-2060]. StatisticsSweden; 2015

183. Marengoni A, Winblad B, Karp A, Fratiglioni L. Prevalence of chronic diseases and multimorbidity among the elderly population in Sweden. Am J Public Health. 2008;98(7):1198200

184. Hovstadius B, Astrand B, Petersson G. Dispensed drugs and multiple medications in the Swedish population: an individual-based register study. BMC Clin Pharmacol. 2009;9:11

185. Richardson K, Moore P, Peklar J. The Irish Longitudinal Study on Ageing; 2012

186. Dang T, Antolin P, Oxley H. Fiscal implications of ageing: projections of age-related spending. OECD Economics Department Working Papers, No. 305, OECD Publishing. 2001

187. Gemmill M. Chronic Disease Management in Europe European Commission. 2008

188. Moher D, Liberati A, Tetzlaff J, Altman DG, PRISMA Group. Preferred reporting items for systematic reviews and meta-analyses: the PRISMA statement. BMJ. 2009;339:b2535 
189. Swedish Tax Agency. Population registration in Sweden. Swedish Tax Agency; 2014

190. Ludvigsson JF, Otterblad-Olausson P, Pettersson BU, Ekbom A. The Swedish personal identity number: possibilities and pitfalls in healthcare and medical research. Eur J Epidemiol. 2009;24(11):659-67

191. Statistics Sweden. Longitudinal integration database for health insurance and labour market studies (LISA) 1990-2009. [In Swedish: Longitudinell integrationsdatabas för Sjukförsäkringsoch Arbetsmarknadsstudier (LISA) 1990-2009]. Örebro: Statistics Sweden; 2011

192. Wettermark B, Hammar N, Fored CM, Leimanis A, Otterblad Olausson P, Bergman U, et al. The new Swedish Prescribed Drug Register--opportunities for pharmacoepidemiological research and experience from the first six months. Pharmacoepidemiol Drug Saf. 2007;16(7):726-35.

193. Swedish National Board of Health and Welfare. The National patient register. Available from: http://www.socialstyrelsen.se/register/halsodataregister/patientregistret/inenglish. Accessed 9/18/2015

194. Wirehn AB, Karlsson HM, Carstensen JM. Estimating disease prevalence using a population-based administrative healthcare database. Scand J Public Health. 2007;35(4):424-31

195. Hakkarainen KM, Andersson Sundell K, Petzold M, Hagg S. Prevalence and perceived preventability of self-reported adverse drug events--a population-based survey of 7099 adults. PLoS One. 2013;8(9):e73166

196. Brvar M, Fokter N, Bunc M, Mozina M. The frequency of adverse drug reaction related admissions according to method of detection, admission urgency and medical department specialty. BMC Clin Pharmacol. 2009;9:8

197. Howard RL, Avery AJ, Howard PD, Partridge M. Investigation into the reasons for preventable drug related admissions to a medical admissions unit: observational study. Qual Saf Health Care. 2003;12(4):280-5

198. Gandhi TK, Weingart SN, Borus J, Seger AC, Peterson J, Burdick E, et al. Adverse drug events in ambulatory care. N Engl J Med. 2003;348(16):1556-64

199. Isacson D, Johansson L, Bingefors K. Nationwide survey of subjectively reported adverse drug reactions in Sweden. Ann Pharmacother. 2008;42(3):347-53

200. DerSimonian R, Laird N. Meta-analysis in clinical trials. Control Clin Trials. 1986;7(3):17788

201. Medical Dictionary for Regulatory Activities. Introductory Guide MedDRA Version 14.0, Document MSSO-DI-6003-14.0.0. Geneva; 2011

202. Swedish National Board of Health and Welfare. Diagnosis Related Groups. Available from: http://www.socialstyrelsen.se/klassificeringochkoder/norddrg. Accessed 9/18/2015 
203. Belfrage B, Koldestam A, Sjoberg C, Wallerstedt SM. Prevalence of suboptimal drug treatment in patients with and without multidose drug dispensing--a cross-sectional study. Eur J Clin Pharmacol. 2014;70(7):867-72

204. O'Mahony D, O'Sullivan D, Byrne S, O'Connor MN, Ryan C, Gallagher P.

STOPP/START criteria for potentially inappropriate prescribing in older people: version 2 . Age Ageing 2015; 44:213-8

205. Hosmer D, Lemeshow S. Applied logistic regression 2nd edition. New York: Chicheter: Wiley; 2000.

206. World Medical Association. Declaration of Helsinki Ethical Principles for Medical Research Involving Human Subjects. World Medical Association; 2008

207. Van der Hooft CS, Dieleman JP, Siemes C, Aarnoudse AJ, Verhamme KM, Stricker BH, et al. Adverse drug reaction-related hospitalisations: a population-based cohort study.

Pharmacoepidemiol Drug Saf. 2008;17(4):365-71

208. Chan M, Nicklason F, Vial JH. Adverse drug events as a cause of hospital admission in the elderly. Intern Med J. 2001;31(4):199-205

209. Franceschi M, Scarcelli C, Niro V, Seripa D, Pazienza AM, Pepe G, et al. Prevalence, clinical features and avoidability of adverse drug reactions as cause of admission to a geriatric unit: a prospective study of 1756 patients. Drug Saf. 2008;31(6):545-56

210. Courtman BJ, Stallings SB. Characterization of drug-related problems in elderly patients on admission to a medical ward. Can J Hosp Pharm. 1995;48(3):161-6

211. Alexopoulou A, Dourakis SP, Mantzoukis D, Pitsariotis T, Kandyli A, Deutsch M, et al. Adverse drug reactions as a cause of hospital admissions: a 6-month experience in a single center in Greece. Eur J Intern Med. 2008;19(7):505-10

212. Baniasadi S, Fahimi F, Shalviri G. Developing an adverse drug reaction reporting system at a teaching hospital. Basic Clin Pharmacol Toxicol. 2008;102(4):408-11

213. Dartnell JG, Anderson RP, Chohan V, Galbraith KJ, Lyon ME, Nestor PJ, et al. Hospitalisation for adverse events related to drug therapy: incidence, avoidability and costs. Med J Aust. 1996;164(11):659-62

214. Davies EC, Green CF, Mottram DR, Pirmohamed M. Adverse drug reactions in hospital inpatients: a pilot study. J Clin Pharm Ther. 2006;31(4):335-41

215. Davies EC, Green CF, Taylor S, Williamson PR, Mottram DR, Pirmohamed M. Adverse drug reactions in hospital in-patients: a prospective analysis of 3695 patient-episodes. PLoS One. 2009;4(2):e4439

216. Dormann H, Criegee-Rieck M, Neubert A, Egger T, Geise A, Krebs S, et al. Lack of awareness of community-acquired adverse drug reactions upon hospital admission: Dimensions and consequences of a dilemma. Drug Saf. 2003;26(5):353-62 
217. Dormann H, Neubert A, Criegee-Rieck M, Egger T, Radespiel-Troger M, Azaz-Livshits T, et al. Readmissions and adverse drug reactions in internal medicine: the economic impact. J Intern Med. 2004;255(6):653-63

218. Farcas A, Sinpetrean A, Mogosan C, Palage M, Vostinaru O, Bojita M, et al. Adverse drug reactions detected by stimulated spontaneous reporting in an internal medicine department in Romania. Eur J Intern Med. 2010;21(5):453-7

219. Gholami K, Shalviri G. Factors associated with preventability, predictability, and severity of adverse drug reactions. Ann Pharmacother. 1999;33(2):236-40

220. Hopf Y, Watson M, Williams D. Adverse-drug-reaction related admissions to a hospital in Scotland. Pharm World Sci. 2008;30(6):854-62

221. Olivier P, Boulbes O, Tubery M, Lauque D, Montastruc JL, Lapeyre-Mestre M. Assessing the feasibility of using an adverse drug reaction preventability scale in clinical practice: a study in a French emergency department. Drug Saf. 2002;25(14):1035-44

222. Patel KJ, Kedia MS, Bajpai D, Mehta SS, Kshirsagar NA, Gogtay NJ. Evaluation of the prevalence and economic burden of adverse drug reactions presenting to the medical emergency department of a tertiary referral centre: a prospective study. BMC Clin Pharmacol. 2007;7:8

223. Pearson TF, Pittman DG, Longley JM, Grapes ZT, Vigliotti DJ, Mullis SR. Factors associated with preventable adverse drug reactions. Am J Hosp Pharm. 1994;51(18):2268-72

224. Pirmohamed M, James S, Meakin S, Green C, Scott AK, Walley TJ, et al. Adverse drug reactions as cause of admission to hospital: prospective analysis of 18820 patients. BMJ. 2004;329(7456):15-9

225. Pourseyed S, Fattahi F, Pourpak Z, Gholami K, Shariatpanahi SS, Moin A, et al. Adverse drug reactions in patients in an Iranian department of internal medicine. Pharmacoepidemiol Drug Saf. 2009;18(2):104-10

226. Ruiz B, Garcia M, Aguirre U, Aguirre C. Factors predicting hospital readmissions related to adverse drug reactions. Eur J Clin Pharmacol. 2008;64(7):715-22

227. Tafreshi MJ, Melby MJ, Kaback KR, Nord TC. Medication-related visits to the emergency department: a prospective study. Ann Pharmacother. 1999;33(12):1252-7

228. Zed PJ, Abu-Laban RB, Balen RM, Loewen PS, Hohl CM, Brubacher JR, et al. Incidence, severity and preventability of medication-related visits to the emergency department: a prospective study. CMAJ. 2008;178(12):1563-9

229. Gallagher P, Barry P, O'Mahony D. Inappropriate prescribing in the elderly. J Clin Pharm Ther. 2007;32(2):113-21

230. Guaraldo L, Cano FG, Damasceno GS, Rozenfeld S. Inappropriate medication use among the elderly: a systematic review of administrative databases. BMC Geriatr. 2011;11:79 
231. Hamilton H, Gallagher P, Ryan C, Byrne S, O'Mahony D. Potentially inappropriate medications defined by STOPP criteria and the risk of adverse drug events in older hospitalized patients. Arch Intern Med. 2011;171(11):1013-9.

232. Rongen S, Kramers C, O'Mahony D, Feuth TB, Olde Rikkert MG, Ahmed AI. Potentially inappropriate prescribing in older patients admitted to psychiatric hospital. Int J Geriatr Psychiatry 2015. [Epub ahead of print] doi: 10.1002/gps.4302

233. Hill-Taylor B, Sketris I, Hayden J, Byrne S, O'Sullivan D, Christie R. Application of the STOPP/START criteria: a systematic review of the prevalence of potentially inappropriate prescribing in older adults, and evidence of clinical, humanistic and economic impact. J Clin Pharm Ther. 2013;38(5):360-72

234. M.D. Conejos Miquel, M. Sánchez Cuervo, E. Delgado Silveira, I. Sevilla Machuca, S. González-Blazquez, B. Montero Errasquin, et al. Potentially inappropriate drug prescription in older subjects across health care settings. European Geriatric Medicine. 2010;1(1):9-14

235. Ryan C, O'Mahony D, Kennedy J, Weedle P, Byrne S. Potentially inappropriate prescribing in an Irish elderly population in primary care. Br J Clin Pharmacol. 2009;68(6):936-47

236. Parsons C, Johnston S, Mathie E, Baron N, Machen I, Amador S, et al. Potentially inappropriate prescribing in older people with dementia in care homes: a retrospective analysis. Drugs Aging. 2012;29(2):143-55

237. Bradley MC, Motterlini N, Padmanabhan S, Cahir C, Williams T, Fahey T, et al. Potentially inappropriate prescribing among older people in the United Kingdom. BMC Geriatr. 2014;14:72

238. Fialova D, Onder G. Medication errors in elderly people: contributing factors and future perspectives. Br J Clin Pharmacol. 2009;67(6):641-5

239. Harbers MM, Achterberg PW. Europeans of retirement age: chronic diseases and economic activity. Bilthoven: National Institute for Public Health and the Environment (The Netherlands); 2012. p. 249

240. Pasina L, Djade CD, Tettamanti M, Franchi C, Salerno F, Corrao S, et al. Prevalence of potentially inappropriate medications and risk of adverse clinical outcome in a cohort of hospitalized elderly patients: results from the REPOSI Study. J Clin Pharm Ther. 2014;39(5):5115

241. Corsonello A, Pedone C, Lattanzio F, Lucchetti M, Garasto S, Di Muzio M, et al. Potentially inappropriate medications and functional decline in elderly hospitalized patients. J Am Geriatr Soc. 2009;57(6):1007-14

242. Page RL, Ruscin JM. The risk of adverse drug events and hospital-related morbidity and mortality among older adults with potentially inappropriate medication use. Am J Geriatr Pharmacother. 2006;4(4):297-305

243. Bates DW, Cullen DJ, Laird N, et al. Incidence of adverse drug events and potential adverse drug events: Implications for prevention. ADE Prevention Study Group. JAMA 1995;274(1):2934 
244. Garcia-Gollarte F, Baleriola-Julvez J, Ferrero-Lopez I, Cuenllas-Diaz A, Cruz-Jentoft AJ. An educational intervention on drug use in nursing homes improves health outcomes resource utilization and reduces inappropriate drug prescription. J Am Med Dir Assoc. 2014;15(12):88591

245. Frankenthal D, Lerman Y, Kalendaryev E, Lerman Y. Intervention with the screening tool of older persons potentially inappropriate prescriptions/screening tool to alert doctors to right treatment criteria in elderly residents of a chronic geriatric facility: a randomized clinical trial. J Am Geriatr Soc. 2014;62(9):1658-65

246. Johnell K, Fastbom J. Comparison of prescription drug use between community-dwelling and institutionalized elderly in Sweden. Drugs Aging. 2012;29(9):751-8

247. Baker E, Roberts AP, Wilde K, Walton H, Suri S, Rull G, et al. Development of a core drug list towards improving prescribing education and reducing errors in the $\mathrm{UK}$. Br J Clin Pharmacol. 2011;71(2):190-8

248. Weingart SN, Gandhi TK, Seger AC, Seger DL, Borus J, Burdick E, et al. Patient-reported medication symptoms in primary care. Arch Intern Med. 2005;165(2):234-40

249. De Smet PA, Dautzenberg M. Repeat prescribing: scale, problems and quality management in ambulatory care patients. Drugs. 2004;64(16):1779-800

250. Deandrea S, Lucenteforte E, Bravi F, Foschi R, La Vecchia C, Negri E. Risk factors for falls in community-dwelling older people: a systematic review and meta-analysis. Epidemiology. 2010;21(5):658-68

251. Pit SW, Byles JE, Henry DA, Holt L, Hansen V, Bowman DA. A Quality Use of Medicines program for general practitioners and older people: a cluster randomised controlled trial. Med J Aust. 2007;187(1):23-30

252. Steinman MA, Handler SM, Gurwitz JH, Schiff GD, Covinsky KE. Beyond the prescription: medication monitoring and adverse drug events in older adults. J Am Geriatr Soc. 2011;59(8):1513-20

253. Chu HY, Chen CC, Cheng SH. Continuity of care, potentially inappropriate medication, and health care outcomes among the elderly: evidence from a longitudinal analysis in Taiwan. Med Care. 2012;50(11):1002-9

254. Cullinan S, Fleming A, O'Mahony D, Ryan C, O'Sullivan D, Gallagher P, et al. Doctors' perspectives on the barriers to appropriate prescribing in older hospitalized patients: a qualitative study. Br J Clin Pharmacol. 2015;79(5):860-9

255. Kaur S, Mitchell G, Vitetta L, Roberts MS. Interventions that can reduce inappropriate prescribing in the elderly: a systematic review. Drugs Aging. 2009;26(12):1013-28

256. Swedish National Board of Health and Welfare. Indicators for good medication therapy in the elderly [In Swedish: Indikatorer för god läkemedelsterapi hos äldre]; 2015 
257. Hammar T, Lidstrom B, Petersson G, Gustafson Y, Eiermann B. Potential drug-related problems detected by electronic expert support system: physicians' views on clinical relevance. Int J Clin Pharm. 2015;37(5):941-8

258. Milos V, Rekman E, Bondesson A, Eriksson T, Jakobsson U, Westerlund T, et al. Improving the quality of pharmacotherapy in elderly primary care patients through medication reviews: a randomised controlled study. Drugs Aging. 2013;30(4):235-46

259. Ulfvarson J, Rahmner PB, Fastbom J, Sjoviker S, Karlsson EA. Medication reviews with computerised expert support: evaluation of a method to improve the quality of drug utilisation in the elderly. Int J Health Care Qual Assur. 2010;23(6):571-82

260. Midlov P, Bahrani L, Seyfali M, Hoglund P, Rickhag E, Eriksson T. The effect of medication reconciliation in elderly patients at hospital discharge. Int J Clin Pharm. 2012;34(1):113-9

261. Gillespie U, Alassaad A, Hammarlund-Udenaes M, Morlin C, Henrohn D, Bertilsson M, et al. Effects of pharmacists' interventions on appropriateness of prescribing and evaluation of the instruments' (MAI, STOPP and STARTs') ability to predict hospitalization--analyses from a randomized controlled trial. PLoS One. 2013;8(5):e62401

262. Organisation for Economic Co-operation and Development. Highlights from: a good life in old age? Monitoring and improving quality in long-term care. OECD Publishing; 2013. Available from: http://www.oecd.org/els/health-systems/Sweden-OECD-EC-Good-Time-in-OldAge.pdf. Accessed 9/18/2015

263. Swedish National Board of Health and Welfare and Swedish Association of Local Authorities and Regions. Quality and Efficiency in Swedish Health Care: Regional Comparisons; 2012. Available form:

https://www.socialstyrelsen.se/Lists/Artikelkatalog/Attachments/19072/2013-5-7.pdf. Accessed 9/18/2015

264. Hovstadius B, Petersson G, Hellstrom L, Ericson L. Trends in inappropriate drug therapy prescription in the elderly in Sweden from 2006 to 2013: assessment using national indicators. Drugs Aging. 2014;31(5):379-86

265. Hyre AD, Krousel-Wood MA, Muntner P, Kawasaki L, DeSalvo KB. Prevalence and predictors of poor antihypertensive medication adherence in an urban health clinic setting. J Clin Hypertens. 2007;9(3):179-86

266. Schroeder K, Fahey T, Ebrahim S. How can we improve adherence to blood pressurelowering medication in ambulatory care? Systematic review of randomized controlled trials. Arch Intern Med. 2004;164(7):722-32

267. Schedlbauer A, Davies P, Fahey T. Interventions to improve adherence to lipid lowering medication. Cochrane Database Syst Rev. 2010;(3):CD004371

268. Cramer JA. A systematic review of adherence with medications for diabetes. Diabetes Care. 2004;27(5):1218-24 
269. The Dental and Pharmaceutical Benefits Agency. Act (2002:160) on Pharmaceutical Benefits; 2002. Available from: http://www.tlv.se/Upload/English/ENG-act-2002-160.pdf. Accessed 9/18/2015

270. Jin J, Sklar GE, Min Sen Oh V, Chuen Li S. Factors affecting therapeutic compliance: A review from the patient's perspective. Ther Clin Risk Manag. 2008;4(1):269-86

271. Briesacher BA, Gurwitz JH, Soumerai SB. Patients at-risk for cost-related medication nonadherence: a review of the literature. J Gen Intern Med. 2007;22(6):864-71

272. Jones I, Britten N. Why do some patients not cash their prescriptions? Br J Gen Pract. 1998;48(426):903-5

273. Turner BJ, Hollenbeak CS, Weiner M, Ten Have T, Tang SS. Effect of unrelated comorbid conditions on hypertension management. Ann Intern Med. 2008;148(8):578-86

274. Qvarnstrom M, Kahan T, Kieler H, Brandt L, Hasselstrom J, Bengtsson Bostrom K, et al. Persistence to antihypertensive drug treatment in Swedish primary healthcare. Eur J Clin Pharmacol. 2013;69(11):1955-64

275. Marshall IJ, Wolfe CD, McKevitt C. Lay perspectives on hypertension and drug adherence: systematic review of qualitative research. BMJ. 2012;345:e3953.

276. Kirkman MS, Rowan-Martin MT, Levin R, Fonseca VA, Schmittdiel JA, Herman WH, et al. Determinants of Adherence to Diabetes Medications: Findings From a Large Pharmacy Claims Database. Diabetes Care. 2015;38(4):604-9

277. Nieuwlaat R, Wilczynski N, Navarro T, Hobson N, Jeffery R, Keepanasseril A, et al. Interventions for enhancing medication adherence. Cochrane Database Syst Rev. 2014;11:CD000011

278. DiMatteo MR, Giordani PJ, Lepper HS, Croghan TW. Patient adherence and medical treatment outcomes: a meta-analysis. Med Care. 2002;40(9):794-811

279. Simpson SH, Eurich DT, Majumdar SR, Padwal RS, Tsuyuki RT, Varney J, et al. A metaanalysis of the association between adherence to drug therapy and mortality. BMJ. 2006;333(7557):15

280. Mazzaglia G, Ambrosioni E, Alacqua M, Filippi A, Sessa E, Immordino V, et al. Adherence to antihypertensive medications and cardiovascular morbidity among newly diagnosed hypertensive patients. Circulation. 2009;120(16):1598-605

281. Perreault S, Dragomir A, Roy L, White M, Blais L, Lalonde L, et al. Adherence level of antihypertensive agents in coronary artery disease. Br J Clin Pharmacol. 2010;69(1):74-84

282. Rasmussen JN, Chong A, Alter DA. Relationship between adherence to evidence-based pharmacotherapy and long-term mortality after acute myocardial infarction. JAMA.

2007;297(2):177-86 
283. Brookhart MA, Patrick AR, Dormuth C, Avorn J, Shrank W, Cadarette SM, et al. Adherence to lipid-lowering therapy and the use of preventive health services: an investigation of the healthy user effect. Am J Epidemiol. 2007;166(3):348-54

284. Granger BB, Swedberg K, Ekman I, Granger CB, Olofsson B, McMurray JJ, et al. Adherence to candesartan and placebo and outcomes in chronic heart failure in the CHARM programme: double-blind, randomised, controlled clinical trial. Lancet. 2005;366(9502):2005-11

285. Ford ES, Mokdad AH, Giles WH, Mensah GA. Serum total cholesterol concentrations and awareness, treatment, and control of hypercholesterolemia among US adults: findings from the National Health and Nutrition Examination Survey, 1999 to 2000. Circulation. 2003;107(17):2185-9

286. Lowy A, Munk VC, Ong SH, Burnier M, Vrijens B, Tousset EP, et al. Effects on blood pressure and cardiovascular risk of variations in patients' adherence to prescribed antihypertensive drugs: role of duration of drug action. Int J Clin Pract. 2011;65(1):41-53

287. Gwadry-Sridhar FH, Manias E, Lal L, Salas M, Hughes DA, Ratzki-Leewing A, et al. Impact of interventions on medication adherence and blood pressure control in patients with essential hypertension: a systematic review by the ISPOR medication adherence and persistence special interest group. Value Health. 2013;16(5):863-71

288. Granger BB, Bosworth HB. Medication adherence: emerging use of technology. Curr Opin Cardiol. 2011;26(4):279-87

289. Coleman CI, Limone B, Sobieraj DM, Lee S, Roberts MS, Kaur R, et al. Dosing frequency and medication adherence in chronic disease. J Manag Care Pharm. 2012;18(7):527-39

290. Gupta AK, Arshad S, Poulter NR. Compliance, safety, and effectiveness of fixed-dose combinations of antihypertensive agents: a meta-analysis. Hypertension. 2010;55(2):399-407

291. Burnier M, Wuerzner G, Struijker-Boudier H, Urquhart J. Measuring, analyzing, and managing drug adherence in resistant hypertension. Hypertension. 2013;62(2):218-25

292. Basger BJ, Moles RJ, Chen TF. Development of an aggregated system for classifying causes of drug-related problems. Ann Pharmacother. 2015;49(4):405-18

293. Läns-SLAKO Östergötland. Elderly report for Östergötland 2011 [n Swedish: Äldrerapport för Östergötland 2011]; 2012

294. Cherubini A, Corsonello A, Lattanzio F. Underprescription of beneficial medicines in older people: causes, consequences and prevention. Drugs Aging. 2012;29(6):463-75

295. Peterson AM, Nau DP, Cramer JA, Benner J, Gwadry-Sridhar F, Nichol M. A checklist for medication compliance and persistence studies using retrospective databases. Value Health. 2007;10(1):3-12

296. Fischer MA, Stedman MR, Lii J, Vogeli C, Shrank WH, Brookhart MA, et al. Primary medication non-adherence: analysis of 195,930 electronic prescriptions. J Gen Intern Med. 2010;25(4):284-90 
297. Franklin JM, Krumme AA, Tong AY, Shrank WH, Matlin OS, Brennan TA, et al. Association between trajectories of statin adherence and subsequent cardiovascular events. Pharmacoepidemiol Drug Saf. 2015;24(10):1105-13

298. Hasselstrom J, Zarrinkoub R, Holmquist C, Hjerpe P, Ljungman C, Qvarnstrom M, et al. The Swedish Primary Care Cardiovascular Database (SPCCD): 74751 hypertensive primary care patients. Blood Press. 2014;23(2):116-25

299. Staessen JA, Den Hond E, Celis H, Fagard R, Keary L, Vandenhoven G, et al.

Antihypertensive treatment based on blood pressure measurement at home or in the physician's office: a randomized controlled trial. JAMA. 2004;291(8):955-64

300. Jarernsiripornkul N, Krska J, Capps PA, Richards RM, Lee A. Patient reporting of potential adverse drug reactions: a methodological study. Br J Clin Pharmacol. 2002;53(3):318-25

301. Sorensen HT, Sabroe S, Olsen J. A framework for evaluation of secondary data sources for epidemiological research. Int J Epidemiol. 1996;25(2):435-42 


\section{APPENDIX \\ Comparison of STOPP and the Swedish National Board of Health and \\ Welfare (Socialstyrelsen) criteria to evaluate PIPs in the elderly}

\section{PIPs criteria present in both STOPP and Socialstyrelsen criteria}

\section{Drug-specific indicators}

\subsection{Drugs that should be avoided unless specific reasons exist}

Long-acting benzodiazepines

Drugs with significant anticholinergic properties (e.g., tricyclic antidepressants ${ }^{2}$, bladder antimuscarinic drugs ${ }^{3}$ )

Tramadol

\subsection{Drugs for which the use requires a correct and current indication}

NSAIDs as analgesics when only treatment with paracetamol is sufficient ${ }^{4}$

Opioids without indication of pain or without first line of mild pain killers

Antipsychotics without existence of indication (psychotic syndrome, severe aggression) ${ }^{5}$

Proton pomp inhibitor (PPI) without appropriate indication (Ulcer disease, Gastro-esophageal reflux disease (GERD), or prophylaxis with NSAIDs)

Loop diuretics without actual known indication ${ }^{6}$

\subsection{Inappropriate dosage regimen}

Antipsychotics $>3$ months without review ${ }^{7}$

Neuroleptics $>3$ months without review ${ }^{8}$

Systemic corticoids $>1$ year without review ${ }^{9}$

\footnotetext{
${ }^{2}$ Excluded in STOPP criteria with diagnosis of glaucoma, cardiac conductive abnormalities, constipation, prostatism or history of urinary retention

${ }^{3}$ Excluded in STOPP criteria with diagnosis dementia, chronic glaucoma, chronic constipation, and chronic prostatism

${ }^{4}$ Non-indicated in in osteoarthritis in STOPP. Both criteria highlight the inappropriateness of NSAIDs in case of heart failure, hypertension, renal failure

${ }^{5}$ Inappropriate indication as hypnotics

${ }^{6}$ For ankle edema or as first line therapy in hypertension

${ }^{7}$ One month in STOPP criteria

${ }^{8}$ One month in STOPP criteria

${ }^{9}$ Maintenance therapy for moderate-severe chronic obstructive pulmonary disease in STOPP
} 


\subsection{Inappropriate daily dose}

Low-dose acetylsalicylic acid (ASA) $>75 \mathrm{mg}^{10}$

\subsection{Polypharmacy}

Drug duplication: Two or more opioids or hypnotics

1.6 Drug combinations that may lead to clinically relevant drug-drug interactions

\subsection{Drug use and renal function}

Metformin, digoxin, potassium-sparing diuretics, atenolol, NSAIDs ${ }^{11}$

\subsection{Drug use and certain symptoms}

Symptomatic orthostatic hypotension: antihypertensives, antipsychotics

Falls: Diuretics, hypnotics, antidepressants ${ }^{12}$

Cognitive impairment: Anticholinergic drugs, opioids, antiepileptics

\subsection{Psychotropic drugs}

Benzodiazepines with long half-time (Diazepam), medications with anticholinergic effects (propiomazine)

\section{Diagnosis-specific indicators}

\subsection{Hypertension}

A combination of a beta-blocker and a cardioselective calcium channel blocker (verapamil, diltiazem)

Cardioselective calcium channel blocker in concurrent heart failure (verapamil, diltiazem)

\subsection{Heart failure}

NSAID or ASA at low dose

Cardioselective calcium channel blocker

\subsection{Chronic obstructive pulmonary disease}

Non-selective b-receptor blocker

Oral theophylline

\footnotetext{
$10150 \mathrm{mg} /$ day in STOPP

${ }^{11}$ NSAIDs, Digoxin in STOPP

12 And first generation antihistamines in STOPP
} 


\subsection{Diabetes, type 2}

Glibenclamide

2.5 GERD and peptic ulcer disease

NSAIDs with a history of GERD or peptic ulcer

PPI for long-term use without review

\subsection{Pain}

NSAIDs in continuous treatment without review ${ }^{13}$

NSAIDs as analgesics when only treatment with paracetamol is sufficient

Opioids without indication of pain or without first line of mild pain killers

\subsection{Dementia}

Drugs with significant anticholinergic properties

General sedation with sedatives or hypnotics

Long-acting benzodiazepines

Antipsychotic drugs for other indications than psychotic symptoms or severe aggression

\subsection{Sleep disturbance}

Long-acting benzodiazepines

Triazolam, propiomazine, alimemazine, hydroxyzine and promethazine

\section{PIPs criteria present only in Socialstyrelsen criteria}

\section{Drug-specific indicators}

\subsection{Drugs for which the use requires a correct and current indication}

Digoxin without indication of atrial fibrillation, or moderate - severe heart failure

\subsection{Inappropriate dosage regimen}

Hypnotics $>1$ month of regular use without review

Antiepileptics $>1$ year without review

NSAIDs in a regular dosage daily for more than two weeks without review

Contact laxatives daily for more than one week, without indication (prophylaxis of constipation during treatment with strong opioids)

\footnotetext{
${ }^{13}$ For osteoarthritis in STOPP
} 
Glucocorticoids for systemic use, in continuous for more than one year without review

\subsection{Inappropriate daily dose}

Risperidone $>1.5 \mathrm{mg}$

Oxazepam $>30 \mathrm{mg}$

Paracetamol, daily dose $>4 \mathrm{~g}$

Haloperidol $>2 \mathrm{mg}$

Zopiclone $>7.5 \mathrm{mg}$

\subsection{Polypharmacy}

Use of ten or more drugs

Use of three or more psychotropic drugs

\section{Diagnosis-specific indicators}

\subsection{Ischemic heart disease-angina pectoris}

Nitrates without free interval in patients with ischemic heart disease or angina pectoris

\subsection{Heart failure}

Digitalis glycoids without presence of atrial fibrillation

Association of potassium as mineral supplement with medications counteracting potassium losses (preparations containing potassium, amiloride or spironolactone)

The non-selective beta-blocker: Sotalol

The antiarrhythmic: disopyramide, propafenone or flecainide

\subsection{Chronic obstructive pulmonary disease}

Oral beta-2-receptor agonists

Inhaled anticholinergics beta-2 stimulants or inhaled steroids without observed effects

\subsection{Diabetes, type 2}

Metformin with decreased renal function (estimated glomerular filtration rate $<60 \mathrm{ml} / \mathrm{min})$

Sulfonylureas in those $\geq 80$ years

Glinide, glitazones, acarbose, incretins, gliptine and glucagon-like peptide receptor agonists

\subsection{GERD and peptic ulcer disease}

Glucocorticoids for systemic use, in combination with NSAID/ASA, without ulcer prophylaxis Potassium

2.6 Pain 
NSAID in continuous treatment without review

NSAIDs in high doses (more than half of the maximum dose. E. $\mathrm{g}>1200 \mathrm{mg}$ for ibuprofen, $>75$ $\mathrm{mg}$ of diclofenac and $>500 \mathrm{mg}$ naproxen, $>4 \mathrm{~g}$ paracetamol)

\subsection{Dementia}

Anticholinesterases or memantine without favourable effect within 6 months

\subsection{Depression}

Prescription of anxiolytics and hypnotics without antidepressant treatment

\section{PIPs criteria only present in STOPP}

\section{Medications acting on the cardiovascular system}

Thiazide diuretics with a history of gout

Calcium channel blocker with chronic constipation ${ }^{14}$

ASA with no history of coronary, cerebral or peripheral arterial symptoms or occlusive arterial event

ASA to treat dizziness not clearly attributable to cerebrovascular disease

Dipyridamole as monotherapy for cardiovascular secondary prevention

Warfarin for first, uncomplicated deep venous thrombosis for longer than six months duration

\section{Medications acting on the central nervous system and psychotropic drugs}

Phenothiazines in patients with epilepsy ${ }^{15}$

Selective serotonin re-uptake inhibitors with a history of clinically significant hyponatraemia

\section{Medication acting on the gastro-intestinal system}

Diphenoxylate, loperamide or codeine phosphate for treatment of diarrhoea of unknown cause ${ }^{14}$ Prochlorperazine (stemetil) or metoclopramide with Parkinsonism

Diphenoxylate, loperamide or codeine phosphate for treatment of severe infective gastroenteritis

\section{Medications acting on the respiratory system}

Nebulised ipratropium with glaucoma

\section{Medications acting on the musculoskeletal system}

Colchicine for chronic treatment of gout where there is no contra-indication to allopurinol

\footnotetext{
${ }^{14}$ Excluded from the new STOPP version

15 Only tricyclic antidepressants included in Socialstyrelsen criteria
} 


\section{Medications acting on the urogenital system}

Alpha-blockers in males with frequent incontinence i.e. one or more episodes of incontinence daily

Alpha-blockers with long-term urinary catheter in situ i.e. more than two months

\section{Medications acting on the endocrine system}

Beta-blockers in those with diabetes mellitus and frequent hypoglycaemic episodes i.e. one episode per month

Oestrogens with a history of breast cancer or venous thromboembolism

Oestrogens without progestogen in patients with intact uterus 


\section{Papers}

The articles associated with this thesis have been removed for copyright reasons. For more details about these see:

http://urn.kb.se/resolve?urn=urn:nbn:se:liu:diva-122266 